NBER WORKING PAPER SERIES

\title{
POLICY INTERVENTION IN DEBT RENEGOTIATION: EVIDENCE FROM THE HOME AFFORDABLE MODIFICATION PROGRAM
}

\author{
Sumit Agarwal \\ Gene Amromin \\ Itzhak Ben-David \\ Souphala Chomsisengphet \\ Tomasz Piskorski \\ Amit Seru \\ Working Paper 18311 \\ http://www.nber.org/papers/w18311
}

\author{
NATIONAL BUREAU OF ECONOMIC RESEARCH \\ 1050 Massachusetts Avenue \\ Cambridge, MA 02138
}

August 2012

The views presented in the paper do not necessarily reflect those of the FRB of Chicago, the Federal Reserve System, the Office of the Comptroller of the Currency, the U.S. Department of the Treasury, or the National Bureau of Economic Research. We thank Raphael Bostic, John Campbell, John Cochrane, Dennis Glennon, Andrew Haughwout, Ali Hortaçsu, Bruce Kruger, Chris Mayer, Uday Rajan, Kristopher Rengert, Johnathan Reuter, Rik Sen, Amir Sufi, Francesco Trebbi, Joe Tracy, Kostas Tzioumis, Wilbert van der Klaauw, Vikrant Vig, and Luigi Zingales. We also thank the seminar participants at Berkeley, Chicago Booth, Chicago Fed, Cleveland Fed, Columbia, Kellogg, NYU Stern, Penn State, Office of the Comptroller of the Currency, Sveriges Riksbank, as well as participants at the AEA, NBER Summer Institute, the NYC Real Estate Conference, the Texas Aim Conference, and the UCLA Real Estate Conference for helpful suggestions. Vera Chau, Monica Clodius, Sam Liu, Regina Villasmil, Zach Wade, and James Witkin provided outstanding research assistance. Piskorski acknowledges the funding from the Paul Milstein Center for Real Estate at Columbia Business School and the NSF (Grant 1124188). Seru acknowledges the funding from the Initiative on Global Markets at Booth School of Business at the University of Chicago.

NBER working papers are circulated for discussion and comment purposes. They have not been peer-reviewed or been subject to the review by the NBER Board of Directors that accompanies official NBER publications.

(C) 2012 by Sumit Agarwal, Gene Amromin, Itzhak Ben-David, Souphala Chomsisengphet, Tomasz Piskorski, and Amit Seru. All rights reserved. Short sections of text, not to exceed two paragraphs, may be quoted without explicit permission provided that full credit, including (C) notice, is given to the source. 
Policy Intervention in Debt Renegotiation: Evidence from the Home Affordable Modification Program

Sumit Agarwal, Gene Amromin, Itzhak Ben-David, Souphala Chomsisengphet, Tomasz Piskorski, and Amit Seru

NBER Working Paper No. 18311

August 2012, Revised June 2016

JEL No. E60,E65,G18,G21,H3

\section{ABSTRACT}

We evaluate the effects of the 2009 Home Affordable Modification Program (HAMP) that provided intermediaries with sizeable financial incentives to renegotiate mortgages. HAMP increased intensity of renegotiations and prevented substantial number of foreclosures but reached just one-third of its targeted indebted households. This shortfall was in large part due to low renegotiation intensity of a few large intermediaries and was driven by intermediary-specific factors. Exploiting regional variation in the intensity of program implementation by intermediaries suggests that the program was associated with lower rate of foreclosures, consumer debt delinquencies, house price declines, and an increase in durable spending.

Sumit Agarwal

Professor of Finance and Real Estate

NUS Business School

Mochtar Raidy Building, BIZ1

15 Kent Ridge Road

Singapore, 119245

ushakri@yahoo.com

Gene Amromin

Federal Reserve Bank of Chicago

230 South LaSalle Street

Chicago, IL 60604-1413

gamromin@frbchi.org

Itzhak Ben-David

Department of Finance

Fisher College of Business

The Ohio State University

2100 Neil Avenue

Columbus, OH 43210

and NBER

bendavid@fisher.osu.edu
Souphala Chomsisengphet

Economics Department

Office of the Comptroller of the Currency

4007 th Street SW

Washington, DC 20219

souphala.chomsisengphet@occ.treas.gov

Tomasz Piskorski

Columbia Business School

3022 Broadway

Uris Hall 810

New York, NY 10027

and NBER

tp2252@columbia.edu

Amit Seru

Booth School of Business

University of Chicago

5807 South Woodlawn Avenue

Chicago, IL 60637

and NBER

amit.seru@chicagobooth.edu 


\section{Introduction}

At least since the Great Depression, federal and state governments have regularly intervened in mortgage markets-through household debt relief and foreclosure prevention polices-during times of exceptionally harsh economic conditions. ${ }^{1}$ There has been a longstanding debate among economists on effects of such interventions. Remarkably, empirical evidence on whether such policy programs are effective is scant. ${ }^{2}$ This paper fills this gap by evaluating the effects of the largest government intervention concerning mortgage debt renegotiation in the aftermath of the recent crisis, the Home Affordable Modification Program (HAMP). The program, as is typical of debt relief programs, relied on voluntary participation of intermediaries (bank servicers) handling mortgages by providing them sizeable financial incentives to renegotiate distressed residential loans. ${ }^{3}$

Our paper has two objectives. First, we assess how the program affected renegotiation decision by servicers, studying renegotiations done under the program as well as outside it. Second, we document substantial heterogeneity in program response across intermediaries and seek to understand its sources. Our main conclusion is that intermediary-specific factors, such as their organizational capacity and infrastructure investments, are an important determinant of renegotiations, impacting the ability of millions of households to avoid foreclosure. This heterogeneity in the ability of intermediaries to implement HAMP also allows us to examine the impact of the program on broader outcomes such as house prices and spending. Beyond the debate on the causes of the recent foreclosure crisis, this finding has implications for design of effective policy interventions, not just debt relief programs, which similarly require voluntary participation of intermediaries for their implementation.

Our unique data contains precise information on performance and renegotiation outcomes for more than $60 \%$ of outstanding residential mortgages in the United States. It is a loan-level panel that has detailed information on loan, property, and borrower characteristics (e.g., interest rates, location of the property, credit scores), payment history (e.g., delinquent or not), renegotiation actions taken (e.g., principal reduction), whether the renegotiation was undertaken under HAMP, as well as the servicer responsible for the mortgage. The richness of this data set provides us a unique opportunity to assess the effects of the program.

\footnotetext{
${ }^{1}$ See (e.g., Rucker and Alston 1987; Posner and Zingales 2009; Kutcher and Stroebel 2008; Scharfstein and Sunderam 2011; Eberly and Krishnamurthy 2014; Rajan and Ramcharan 2015)

${ }^{2}$ Proponents argue that such policies prevent excessive foreclosures that may otherwise lead to deadweight losses for borrowers and lenders, especially if debt contracts are incomplete (Bolton and Rosenthal 2002) and generate negative externalities for the society (Campbell et al. 2011; Guiso et al. 2013; Melzer 2010). Critics argue that such policies potentially generate moral hazard problems that are likely to raise the cost of credit in the long run.

${ }^{3}$ HAMP was passed to alleviate several perceived barriers to renegotiation. There was a one-time incentive payments to servicers of $\$ 1,000$ for each completed renegotiation under the program. Servicers were also eligible for up to $\$ 1,000$ in annual, ongoing pay-for-success incentive payments. These incentive payments are sizeable relative to the regular annual fees for servicing, which amount to about twenty to fifty basis points of the outstanding loan balance ( $\sim 400$ to $\$ 1,000$ per year for a $\$ 200,000$ mortgage). See Section II.C for more discussion.
} 
The biggest obstacle, however, in evaluating the impact of the program on outcomes such as mortgage renegotiation and foreclosure rates is getting an estimate of the counterfactual level of these outcomes in the absence of the program. We circumvent this issue by using a variety of empirical designs that exploit variation in exposure of similar borrowers to the program.

The main empirical strategy (Strategy I) exploits variation in owner-occupancy status since the original formulation of HAMP did not allow renegotiation for mortgages backed by investorowned properties. We use such borrowers as a control group for the eligible group of borrowers whose property is classified as owner-occupied (treatment group). The second strategy (Strategy II) uses the program rule that mortgages on owner-occupied properties with outstanding balances above \$729,750 are ineligible for HAMP, which allows us to construct the treatment and control groups of borrowers on either side of this loan balance threshold. Since this strategy exploits eligibility criteria based on loan amount within the group of loans for owner-occupied properties, it sharpens the comparisons between treatment and control groups of the first strategy.

The third strategy (Strategy III) is based on another program criteria of passing the Net Present Value (NPV) test that is conducted among loans that satisfy all other criteria. Exploiting variation around the eligibility threshold of this test, among otherwise similar loans, allows us to investigate a direct effect of the program-induced modifications on foreclosure rate. Finally, the fourth strategy (Strategy IV) exploits the change in HAMP rules in mid-2012 that allowed some loans that financed non-owner-occupied properties to be eligible for renegotiation. We assess the effect of the program on these loans - a part of the control group of our main empirical strategy - once they become eligible. To the extent that our main empirical strategy is reasonably designed, we expect effects that are similar to those in treatment loans (owner-occupant loans).

We start by showing that, on average, control and treatment groups in all empirical strategies are similar and have no differential pre-trends. This holds for various observables such as credit score, loan-to-value ratio, interest rates, delinquency rates as well as rate of renegotiations. As a validation of our empirical design, we verify that loans classified into treatment group based on the program guidelines are the ones where HAMP renegotiations (modifications) are performed.

Next, we analyze the extensive margin - that is, additional loan renegotiations induced by the program. We take into account the potential of the program to crowd out modifications performed by the servicers outside of the program (i.e., "private modifications"). We find that there is some decline in the rate of private modifications in the eligible group relative to the control group. Consequently, one program modification effectively induces about 0.84 more net modifications. We discuss potential reasons for why the program may not have crowded out private modification activity significantly. 
We further show that HAMP affected the distribution of modification types - the intensive margin - performed inside and outside the program. We find that servicers channeled some loans that they would have modified based on their private incentives to be modified under HAMP instead. Private permanent modifications offered in the treatment group after the program is introduced become less aggressive (e.g., fewer rate reductions and interest capitalizations) and suffer a drop in their effectiveness, as measured by default rate subsequent to the modification. There is a concurrent increase in aggressiveness and effectiveness of modifications done under the HAMP, which offsets the drop in effectiveness of private modifications. As a result, there is no significant change in the average effectiveness of modifications in the treatment group.

Overall, when considering all the renegotiations-regardless of whether they were done privately or under HAMP — we find that the program led to a net increase in the annual rate of permanent modifications of about 0.57 percentage points. ${ }^{4}$ At our estimated rate, the program would induce about 1 million additional permanent modifications over its original duration (i.e., through December 2012)_falling significantly short of its goal of three to four million modifications for the severely indebted households targeted by the intervention.

We then turn to examining the impact of HAMP on the outcome it was designed to ultimately affect - that is, the rate at which loans are foreclosed. We find that HAMP resulted in a decrease in the rate of completed foreclosures in the treatment group, reflecting the change in extensive margin induced by the program. In particular, we observe a differential 0.37 percentage points decrease in the annual foreclosure rate across the loans in the treatment group. This rate would translate into about 600,000 fewer foreclosures over the original duration of the program (i.e., through December 2012) — a significant impact but one that is substantially lower than the program target. Finally, our evidence also suggests that HAMP did not lead to widespread strategic delinquencies - i.e., missing loan payments to increase chances of being considered for the program modification -- likely reflecting the extensive screening related to its eligibility criteria and design of incentives for servicers.

These results come from our main identification strategy. We next turn to various tests that assess the potential shortcomings of this empirical design. First, our alternative empirical strategy that exploits variation around the balance eligibility cut-off provides comfort on external validity. Moreover, we provide several pieces of additional evidence that confirm the validity of our empirical strategy based on the owner-occupancy status. In particular, we exploit the change in the program rules from mid-2012 that made a subset of loans with non-owner occupancy status eligible for HAMP. We find similar effects in these loans after the change in rules as in

\footnotetext{
${ }^{4}$ The program also induced several trial modifications-renegotiations that had to be necessarily offered under the program for a trial period before permanent ones could be offered. The rate of trial HAMP modifications is higher than permanent ones, and about $53 \%$ of trial modifications were converted into permanent ones. This conversion rate reflects several criteria that had to be satisfied before a trial modification could be made permanent.
} 
our treatment group. Finally, we also assess if our treatment effects might be inflated because the program incentives might have led some servicers to reallocate their resources for conducting HAMP modifications in the treatment group at the expense of modifications in the control group. To address this, we focus on a subset of servicers who did not participate in HAMP and compare renegotiations in loans of these intermediaries with those in our original control group. This analysis, as well as other tests, suggests that the rate of modifications in the control group was unchanged.

The above estimates capture the impact of the program on foreclosure rate through multiple channels such as the combined effect of trial modifications -- which if successful, can lead to a permanent modification--, permanent HAMP modifications, changes in the number and composition of private modifications, and the program's impact on other servicing actions that may impact foreclosure rates. We further isolate the impact of the program on foreclosures through its direct effect on permanent modification only. We take advantage of the program requirement that to be approved, the mortgage needed to pass a NPV test demonstrating that permanent modification would result in higher expected repayments to the lenders/investors relative to the case of no modification. Exploiting variation around the eligibility threshold of this test among otherwise similar loans satisfying all other program criteria, we find that program-induced permanent modifications can account for a substantial part of decline in foreclosure rate.

While it is difficult to know what the optimal response to the program incentives should have been, in the second part of the paper we exploit cross-sectional variation in response among intermediaries to shed light on potential barriers to program implementation as well as on broader economic effects in areas most exposed to the program.

We find substantial heterogeneity across servicers in terms of their response to HAMP, with a few large servicers offering modifications at half the rate of others. A simple counterfactual computation shows that this is a large effect-the program would have induced about $70 \%$ more permanent modifications if all the loans by less active servicers were renegotiated at the same rate as those of their more active counterparts. Further investigation shows that the renegotiation activity of servicers during the program closely tracks their preprogram renegotiation behavior. While contract, borrower, and regional characteristics of mortgages are important determinants of renegotiation activity of a servicer, they cannot account for these differential renegotiation patterns. Instead, servicer-specific factors-which seem to be related to their preexisting organizational capabilities-are responsible for differences in preprogram renegotiation activity. Servicers with lower (higher) renegotiation activity had preprogram organizational design that was less (more) conducive to conducting renegotiations on 
dimensions such as size and workload of the servicing staff, staff training effort, and servicing call-center capability. ${ }^{5}$

Finally, we study regional outcome variables such as house prices in regions differentially exposed to the program to assess the effects of debt relief programs, when implemented intensively. To generate variation in program exposure, we exploit regional variation in the share of loans serviced by intermediaries with high pre-program renegotiation activity. Because servicer concentration in a region is determined prior to the program and is very persistent in the data, using this variation seems reasonable. Using this analysis we provide evidence consistent with the notion that debt relief programs such as HAMP, when used with sufficient intensity, could have an impact on foreclosures, delinquencies on non-targeted consumer debt, house prices, and durable consumption.

\section{HAMP: Background, Eligibility, Incentive Plan, and Overall Budget}

\section{II.A Background}

The housing crisis erupted in the second half of 2007, with the number of foreclosures reaching unprecedented levels. More than 700,000 foreclosures were started in 2007, with another two million in 2008 and even more in subsequent years (CoreLogic Data). Foreclosures are considered costly — either because they result in significant deadweight losses for borrowers and lenders or because they result in negative externalities for the society (see Posner and Zingales 2009; Mayer, Morrison, and Piskorski 2009; Campbell et al. 2011). Thus, federal and state government efforts were aimed at encouraging mortgage renegotiations through loan modifications instead of foreclosing on houses backing delinquent mortgage loans.

There were several reasons why the rate of mortgage modifications was perceived to be too low. First, since foreclosures may exert significant negative externalities, it could be socially optimal to modify mortgage contracts to a greater extent than servicers were choosing to do privately. ${ }^{6} \quad$ Second, policy makers noted that the non-agency securitized market-that is, securitized mortgages issued without a guarantee from government-sponsored entities (GSEs) accounted for more than half of the foreclosure starts, despite their relatively small market share. The worry was that high foreclosure rates on these securitized mortgages reflected factors other than their greater inherent credit risk. In particular, a servicer-an intermediary who makes the

\footnotetext{
${ }^{5}$ The fact that some servicers—-with similar loans as servicers with low program response rate-actively conducted modifications under the program suggests that the incentive structure of HAMP may not have been inadequate. Rather, the policy may have failed to account for firm-level factors that resulted in muted program response of some servicers. Our analysis does not allow us to comment on the exact nature of these firm-level factors or how they led to inertia in the behavior of these servicers. For instance, servicers with low renegotiation activity in the pre-program period may not have responded to the program because doing so would have involved changing their business focus (and infrastructure and staff) from processing and channeling payments to actively renegotiating loans.

${ }^{6}$ In times of adverse economic conditions, renegotiating some mortgages instead of foreclosing them could create value for both borrowers and lenders (Bolton and Rosenthal 2002; Piskorski and Tchistyi 2011).
} 
crucial decision to pursue a foreclosure or renegotiate a delinquent mortgage - is an agent who acts on behalf of the investor in case of a securitized loan. Thus, servicers' contractual obligations and legal uncertainty on the course of action allowed by investors could have inhibited renegotiation of securitized loans. ${ }^{7}$

These economic arguments prompted the federal government to intervene in the mortgage market by providing financial incentives to lenders to renegotiate residential mortgages. ${ }^{8}$ On February 19, 2009, President Obama announced the Home Affordable Modification Program (HAMP), which became a central policy tool aimed at bolstering the rate of modifications of residential loans. The program guidelines were presented on March 4, 2009.

\section{II.B Borrower Eligibility}

According to HAMP guidelines, borrowers' eligibility during the program was based on a number of factors. First, the property had to be owner-occupied and the borrower's primary residence. Vacant and investor-owned properties were excluded. Second, the property had to be a single-family (one- to four-unit) property, with a maximum unpaid principal balance on the unmodified first-lien mortgage equal to or less than $\$ 729,750$ for a one-unit property. Third, the loans had to have been originated on or before January 1, 2009. Fourth, the first-lien mortgage payment had to be more than $31 \%$ of the homeowner's gross monthly income in order for the program to reduce the household monthly debt burden to a target of 31\%. In addition, the borrower application for modification had to pass the Net Present Value (NPV) test obtaining a positive value in the test, implying that providing a permanent HAMP modification would yield higher expected payments to the lenders/investors relative to the case of no modification (and potential foreclosure). Finally, the program rules require the servicers to offer a trial modification first, which may be subsequently converted into a permanent modification only if the modification is successful during the trial period (i.e., borrowers make payments per the changed contract that was offered on a trial basis, which typically takes about six months).

We use some of these eligibility criteria to classify borrowers into those who are likely to be affected by HAMP (treatment group) and those who do not qualify (control group). We note that verification of these criteria requires servicers to employ appropriate infrastructure and sufficiently trained staff. For instance, processing applications for program modifications involves direct contact between servicer and borrower, potentially through a call center, in order to collect relevant information.

\section{II.C Incentives for Servicers}

\footnotetext{
${ }^{7}$ Moreover, coordination frictions between multiple investors of securitized debt can make it hard to change the contracts between them and the servicers. Existing research has been consistent with the view that securitization adversely impacted incentives to renegotiate mortgages (Piskorski et al. 2010 and Agarwal et al. 2011).

${ }^{8}$ There could be also some political motivation behind the program. See Mian et al. 2010 on importance of political considerations in legislative process leading to stabilization polices during the recent crisis.
} 
We now discuss the incentive payments for the servicers and lenders who participate in the HAMP program. It is important to note that majority of loans in the U.S. are serviced by banks and these institutions very commonly originate the loans they end up subsequently servicing. Thus, in these cases the match between the borrower and servicer is directly implied by the identity of the lender originating the loan. While we will not study this choice formally, the richness of our data allow us to construct groups of comparable borrowers whose loans are serviced by different banks.

In discussing servicer incentive payments, we focus primarily on the first-lien modification program, which has been the largest component of HAMP. The major feature of the first-lien modification program is its incentive payment structure. The funds from the program were to provide one-time and ongoing "pay-for-success” incentives to loan servicers, mortgage holders/investors, and borrowers. First, there were to be one-time incentive payments to servicers of $\$ 1,000$ for each completed permanent modification under HAMP. Second, servicers were also eligible for up to $\$ 1,000$ in annual, ongoing pay-for-success incentive payments that would accrue when monthly mortgage payments were made on time for three years after the borrower's monthly mortgage payment was permanently modified. In addition, servicers would receive an additional current borrower bonus incentive payment of $\$ 500$ when a loan was permanently modified for a borrower whose loan was current. These incentive payments are quite substantial relative to the regular fees for servicing, which amount to about twenty to fifty basis points of the outstanding loan balance per year (roughly $\$ 400$ to $\$ 1,000$ per year for a mortgage with $\$ 200,000$ of outstanding loan balance; see Barclays 2008).

Mortgage holders/investors would also receive this type of incentive as a one-time payment of $\$ 1,500$ for each modification agreement executed with a borrower who was current on mortgage payments upon entering HAMP. Finally, borrowers who remained current on their mortgage payments would be eligible for up to \$1,000 in annual, ongoing “pay-for-performance” incentives for five years - to be used to pay down the mortgage principal. There was also a costsharing arrangement with mortgage investors for help in reducing first-lien mortgage payments.

While servicer participation in the program was voluntary, many major bank servicers in the United States decided to participate. This includes all the servicers in our main data set. However, as we corroborated in conversations with the economists at the U.S. Department of Treasury, some servicers of non-agency securitized mortgages associated with RMBS deals issued by foreign underwriters opted out of the program. We use an alternative dataset consisting of renegotiations conducted by such servicers to better assess renegotiation activity in the absence of the program.

At the time of its introduction, the program was to remain in force until December 31, 2012. Program payments were to be made for up to five years after the date of entry into a Home 
Affordable Modification. According to the US Government Accountability Office (2009), the overall funds allocated to HAMP were $\$ 75$ billion. The expectation of policy makers-given the number of severely indebted households - was that about three to four million homeowners would receive assistance with their mortgages during forty-five months of the program (from April 2009 till December 2012). ${ }^{9}$ In July 2012, the program's end date was extended till December 31, 2013. In May 2013 it was further extended till December 31, 2015. Finally, in July 2014 it was extended yet again until the end of 2016. In addition, in June 2012 the HAMP owner-occupancy eligibility criteria was relaxed to allow modification of residential mortgages financing rental properties occupied by a tenant or properties available for rent on a year-round basis. Online Appendix A1 summarizes these program rules in a flow chart.

\section{Data}

Our main data source for the analysis is the OCC Mortgage Metrics data. This unique data set includes origination and servicing information for U.S. mortgage servicers owned by large banks supervised by the OCC. The data consist of monthly observations of over 34 million mortgages totaling $\$ 6$ trillion, which make up about $64 \%$ of U.S. residential mortgages. About $11 \%$ of these loans are bank-held, and $89 \%$ are sold to investors through GSEs as well as through the private market. Because of various restrictions implied by our empirical design and the availability of relevant loan characteristics in the data, we end up using about 23 million of these loans in our analysis. ${ }^{10}$ We study loans over the period July 2008 through June 2012. Since HAMP was implemented in March 2009, we have data that span nine months in the period before HAMP was implemented and thirty-nine months of the program period. ${ }^{11}$

The origination details in the data set are similar to those found in other loan-level data (e.g.,CoreLogic LoanPerformance or LPS data). In particular, there is information on original loan terms as well as mortgage, property, and borrower characteristics (e.g., credit score, owneroccupancy, balance, and interest rate). The servicing information is collected monthly and includes details about actual payments, loan status, and changes in loan terms.

The data set contains detailed information about the workout resolution for borrowers. We know if the loan was modified under HAMP-either as a trial or permanent modificationor if it was privately modified by servicers. The data set contains information about the change in contract terms when a modification occurs (e.g., reduction in interest rate, amount of principal

\footnotetext{
${ }^{9}$ This estimate was based on the number of homeowners who were likely to be at risk of default (over 10 million homes), to have unaffordable loans (more than 8 million homes), to apply for a loan modification (5.5 million homes), and to pass the NPV test (about 4 million homes). See U.S. GAO Report, July 2009.

${ }^{10}$ The reason for this attrition is due to the missing values for loan characteristics in the data, mainly their owneroccupancy status. As will become clear, this field is needed to classify the loans into treatment and control groups. We will discuss later why, despite this attrition, we think our sample is reasonably representative of the population.

${ }^{11}$ Relative to earlier versions of our paper, we use a more recent version of the OCC Mortgage Metrics data (from 2013). This allows us to study program effects over a substantially longer horizon relative to previous versions.
} 
deferred or forgiven etc.), and the repayment history before and after the action (current, delinquent, etc.). It also provides information on the identity of the sixteen main servicing entities responsible for the mortgage. This allows us to exploit within-servicer variation as well as variation across servicers. We will also take advantage of additional U.S. Treasury data on a random sample of HAMP applications. This data contains detailed information on various variables that help determine eligibility of each applicant in the HAMP NPV test. As will become clear, this data allow us to assess outcomes among loans that are very similar in terms of variables that enter the NPV test.

We also use a loan-level data set provided by BlackBox Logic that covers almost all securitized mortgages issued without government guarantees. In addition to origination and payment data for each of these loans, this data set also reports whether a mortgage received a private modification in a given month. By merging this data with underwriter data provided by ABSNet, we are able to separately analyze private modification rates for loans in deals handled by servicers who opted out of HAMP. As we will discuss later, this analysis will help investigate the modification trends among servicers who did not participate in the program.

Finally, in our zip-code-level analysis, we use zip-level house price indices from CoreLogic, zip-level auto sales growth data from Mian and Sufi (2010) and data on consumer credit performance from a credit bureau (Equifax).

\section{Empirical Methodology}

\section{IV.A Research Design}

The biggest obstacle in evaluating the impact of the program on outcome variables is to get an estimate of the counterfactual level in the absence of the program. We circumvent this obstacle by exploiting variation in exposure of similar borrowers to HAMP. The key to our empirical design is defining the groups of borrowers that are eligible for HAMP. The main empirical strategy (called Strategy I) exploits variation in owner-occupancy criteria for receiving renegotiation under HAMP to form these groups. Specifically, borrowers whose properties are classified as investor-owned during program implementation are ineligible for HAMP and, therefore, can serve as a control group for the treatment group-namely, the group of borrowers whose properties are classified as owner-occupied. We end our sample in 2012:Q2, given that it is difficult to cleanly classify the treatment and control groups after the numerous institutional changes that occurred after this period. We come back to this issue in Section VI.A.3.

We investigate the validity of this empirical strategy in the data and find support for it when we evaluate various borrower and contractual observables. ${ }^{12}$ In particular, we show that

\footnotetext{
${ }^{12}$ Our data consists of loans serviced by main banking institutions and, in general, includes mortgages of much better average credit quality than typical loans that were used to finance speculative investments in the non-agency
} 
there are no differential trends in how the treatment group compares with the control group before the program is passed (see Meyer 1995). The identification assumption is that in the absence of HAMP and controlling for observables, the difference between treatment and control groups would display similar payment and renegotiation patterns (up to a constant difference) during the period of the program as they did before it. We discuss this in Section IV.B and Section VI.

We rely on the following difference-in-difference specification to estimate the effect of HAMP:

$$
Y_{\mathrm{it}}=\alpha+\beta \times \mathrm{T}_{\mathrm{i}}+\gamma \times \mathrm{T}_{\mathrm{i}} * 1(\text { After })_{\mathrm{it}}+X_{\mathrm{it}} \delta+\varepsilon_{\mathrm{it}},
$$

where $T$ takes a value of 1 for loans in the treatment group and 0 for the loans in the control group. After takes the value of 1 for the quarters after 2009:Q1 (the program period), and 0 otherwise. Loans for owner-occupied properties take a value of $T=1$, while loans for the investor-occupied properties take a value of $T=0$. The occupancy status of these properties is based on information gathered at origination of the loan. We also require that loans in the treatment group have an outstanding balance below the program eligibility cutoff of $\$ 729,750$. The coefficient $\gamma$ measures the effect of the program on the treatment group relative to the control group, while the coefficient $\beta$ measures the pre-program differences between the treatment and control groups. The vector Xit contains a set of borrower, loan, and regional characteristics and includes After.

We estimate these regressions on all mortgages regardless of their payment status. The reason is that while HAMP requires that borrowers must "face economic hardship and a danger of imminent default," the program does not have any specific requirement that a loan has to be delinquent or under water to be eligible. In fact, the program provides additional financial incentives to servicers to actively modify loans that are currently making payments (but may not do so in the future). Nevertheless, one could potentially also conduct the analysis only on delinquent loans, arguing that borrowers with these loans are those most likely to satisfy these criteria. While our results are qualitatively similar to those reported in the paper, we are cautious in following this route. As discussed in Section V.C.2, delinquency status of a loan may itself be a response variable to HAMP - since the program design may itself induce borrowers who would otherwise continue making payments to default (see Mayer et al. 2014).

The first outcome variable employed in these regressions is to assess the extensive margin - that is, whether or not the loan was modified (i.e., Yit=1 if loan $i$ was modified in time occupancy status very comparable in our data (see Haughwout et al. 2011, who show large differences between owner-occupied and investor loans when they investigate the sample of largely non-agency securitized mortgages). 
t). We use several variants of this variable, such as whether the loan was privately modified or was modified under HAMP. To ensure that we track the rate of modifications on loans rather than the cumulative effect, we drop loan observations subsequent to modification when we use a loan in a panel setting. We account for different loan-level attributes that capture observable idiosyncratic differences across borrowers. In particular, Xit is a vector of loan and borrower characteristics that includes variables such as initial FICO credit score, initial and current loanto-value ratio (LTV), and initial interest rate and loan balance. We include controls for loan ownership status: whether a loan is securitized into GSE-backed pools (agency loan), is securitized without government guarantees (private-label loan), or is bank held (portfolio loan). We also employ origination year and servicer fixed effects to absorb any aggregate effects driven by the times at which loans were originated and to capture idiosyncratic servicer-related effects.

In our subsequent specifications, we also investigate the intensive margin-that is, we employ similar regressions to evaluate the likelihood of receiving different types of contractual modifications conditional on receiving one (i.e., Yit=1 if loan $i$ was modified in time $t$ and the modification was of a certain type). Similar regressions are also employed to assess the efficiency of renegotiations by tracking the likelihood of redefault of a loan subsequent to receiving a modification (i.e., Yit $=1$ if loan $i$ was modified in time $t$ and the loan redefaulted within a certain time period from $t$ ) and the likelihood a loan is foreclosed (i.e., Yit=1 if loan $i$ was foreclosed in time $\mathrm{t}$ ).

Finally, note that in specifications that investigate change in renegotiation rate, the loans that default (e.g., become seriously delinquent) do not exit the estimation. Only when these loans are foreclosed do they exit the sample. We include these loans since delinquent mortgages could be considered as plausible candidates for renegotiation. Similarly, in specifications that investigate the change in foreclosure rate, loans that are renegotiated do not exit the estimation sample. Again, these loans are included since they may be plausible candidates for getting foreclosed. In the unreported tests we verify the robustness of our results with respect to these choices.

\section{IV.B Potential Concerns and Alternative Empirical Strategies}

We confront several challenges in the identification of our key estimates. First, we need to show that the treatment and control groups are comparable before the program was implemented. Table 1 presents the descriptive statistics for important observables at the quarterly frequency in the treatment and control groups as defined by our empirical strategy. It reports the statistics in the pre-HAMP period—-that is, from July 2008 to March 2009.

The control group is similar to the treatment group on most observables. In particular, the control group has loans that have, on average, a somewhat higher FICO credit score relative to the treatment group (717 versus 710 ). The mean LTV is about $70 \%$, and about $1.6 \%$ of loans are 
seriously delinquent (payments that are at least two months past due) in both groups. Moreover, interest rate, a statistic that captures the overall riskiness of the borrower pool, is very similar across the two groups (the mean for both is slightly above 6.1\%). The renegotiation rates in the two groups differ a bit in the pre-HAMP period-about $0.3 \%$ of loans obtain private permanent modifications per quarter in the control group and about $0.4 \%$ in the treatment group--but, importantly for our identification, as we will show in Figure 2(b), there are no visible pre-trends in this difference. It is worth noting that not only the means but the computed standard deviations of the two groups are quite similar for all these variables as well. Figure 1 plots the kernel densities of FICO credit score, LTV, and interest rates for the borrowers in the treatment and control groups. The two groups look remarkably similar on all these dimensions. Finally, we note that the observables in the treatment and control groups are not only well matched on average in the pre-treatment period, but they are also matched period by period (Online Appendix A2).

One might worry that, despite the similarity of treatment and control groups on observables, these groups may differ due to owner occupancy status. Notably, our data consist of mortgages serviced by main banking institutions, which are known to be on average of a better quality than the entire population of U.S. mortgages (see Piskorski et al. 2010). This could explain why the control group is well matched with the treatment group in our data. Nevertheless, we provide robustness and external validity of results from Strategy I by using an alternative empirical strategy (Strategy II) in Section VI.A that allays these concerns-both treatment and control groups in this strategy consist of owner-occupied properties with similar observables. Moreover, we conduct tests using treatment and control groups that are formed based on the NPV eligibility test that is conducted among loans satisfying all other eligible criteria (Strategy III and IV). We discuss these and several other related robustness tests in Section VI.

Second, like other studies on program evaluation that use the difference-in-difference strategy (e.g., Mian and Sufi 2010), we will not be able to comment on any economy-wide effects introduced by the program. This includes any across-the-board improvement or worsening in renegotiation process/standards due to the program.

\section{Impact of HAMP: Loan-Level Analysis}

\section{V.A Impact on Extensive Margin: HAMP and Private Modifications}

\section{V.A.1 HAMP Trial and Permanent Modifications}

We first analyze renegotiations induced by the program in the treatment group. We focus on renegotiations that are offered in the form of "trial modifications," and may be subsequently 
converted into "permanent modifications" if the modification is successful during the trial period (i.e., borrowers make payments according to the contract that was offered on a trial basis).

Figure 2(a) presents the fraction of loans that enter trial and permanent HAMP modifications for the first time in a given month in the treatment group, defined by our main empirical strategy. On average, about $0.10 \%$ of loans enter a HAMP trial modification in a month in the treatment group (with the peak being around $0.32 \%$ per month), implying about a $1.2 \%$ annual modification rate. There is a substantial increase in HAMP trial modifications in the treatment group just after the introduction of the program in March 2009. The rate of HAMP trial modifications peaks around late 2009 and then starts to decline. The sharp decline in the number of HAMP trial modifications in the second half of 2010 was related to the tightening of program eligibility rules for such modifications. ${ }^{13}$

Figure 3(a) also presents the fraction of loans that enter permanent HAMP modifications for the first time in a given month in the treatment group. A permanent HAMP modification resulted, on average, in about $25 \%$ reduction in monthly payment--a saving in the order of $\$ 300$ $\$ 400$ per month. There is a substantial increase in HAMP permanent modifications, starting a few months after the program was introduced in March 2009. This pattern is mechanical because, as we discussed earlier, a loan could be given a permanent HAMP modification only subsequent to a successfully completed trial HAMP modification, which usually took at least three months. On average, about $0.056 \%$ of loans per month received a permanent HAMP modification in the treatment group (with a peak of about $0.14 \%$ per month). This translates into about a $0.68 \%$ annual modification rate. As a validation of our empirical design, we verify that loans classified into the treatment group based on the program guidelines are the ones where modifications are performed under HAMP. ${ }^{14}$

Using these estimates we can get a sense of the "conversion rate" from trial modifications to permanent ones. Our findings suggest that about 53\% of HAMP trial modifications were converted into permanent ones. The rate is smaller than $100 \%$ because the program guidelines require the conversion from trial to permanent HAMP modification to be based on several criteria. These include the borrower making the scheduled payments under the terms of the trial modification, as well as the borrower providing the necessary documentation that helps servicers to verify borrowers' eligibility for the program. Table 1 summarizes these findings.

\footnotetext{
13 Prior to June 1, 2010, trial modifications could be initiated even if borrowers did not provide all required documentation to potentially roll them over into permanent modifications. Borrowers required documentation in order to enter the trial modification subsequent to this date. (Directive 10-01 of the U.S. Department of the Treasury)

${ }^{14}$ There are a few program modifications that we observe in the control group. These cases are relatively rare and, importantly, excluding or including them does not impact our inferences. Conversations with servicers suggest that these cases reflect program guidelines that allow for modifications under the program to be offered to borrowers that, at the time of applying for a modification, could credibly show that the property was now their main residence.
} 
Next, we explore the characteristics of mortgages that were more likely to receive a modification under HAMP. We find that mortgages given to borrowers with lower FICO credit score, higher loan-to-value ratios, higher interest rates, and higher loan amounts are more likely to receive both trial and permanent HAMP modifications (see Online Appendix A3). These results are not surprising given that the program targeted loans at risk of default.

Overall, we find that HAMP induced a sizeable number of modifications in the eligible group of loans. However, this does not necessarily mean that the program increased the overall rate of modifications performed by the servicers, as it may also have affected the modifications outside of the program (that is, private modifications). We investigate this issue in the next section.

\section{V.A.2 Private Permanent and Overall Modifications}

We explore the effects of HAMP on renegotiations done by servicers based on their private incentives outside the program (private modifications). In Table 2, we test whether HAMP affected the rate of permanent private modifications in the treatment group. We focus on permanent private modifications, since these renegotiations have been shown to be the main renegotiation tool for loss mitigation in the period before the program (Agarwal et al. 2011). The impact of HAMP on private modification rates in the treatment group relative to the control group can be identified by the coefficient on $T^{*}$ After. The coefficient estimates in Columns (1)(3) suggest that the rate of private permanent modifications in the treatment group (about $0.6 \%$ private permanent modification rate on quarterly basis) decreased slightly relative to the control group after the program's introduction (about $0.025 \%$ reduction on a quarterly basis). This finding suggests that the program did not result in a substantial change in the rate of private modifications in the treatment group. ${ }^{15}$

These patterns are visible in Figure 2(b), where we present the fraction of loans that enter permanent private modification for the first time in any given month in the control and treatment groups. Consistent with our estimates there is no meaningful relative change in the quarterly private permanent modification rate in the treatment group during the program. To investigate this further, we re-estimate the specification in Table 2 where we replace the After dummy with quarterly dummies and their interactions with the treatment dummy (the excluded category includes observations from 2008:Q3). This specification allows us to investigate the quarter-byquarter changes in private modification rate between the treatment and control groups. We again

\footnotetext{
${ }^{15}$ Throughout the paper we cluster standard errors at the state level corresponding to the location of the property backing the loan. The results are also robust to clustering at the loan level. We estimate our specifications using the OLS despite the binary nature of several of the dependent variables. The reason is that we have a large number of fixed effects along several dimensions, and using logit or probit results in an incidental parameters problem. Our OLS specification with flexible controls to capture nonlinearity allows us to estimate our coefficients consistently even with multiple fixed effects (Dinardo and Johnston 1996). We obtain qualitatively similar inferences when employing a logit without as many fixed effects.
} 
find no evidence that the program resulted in a meaningful change in the private modification rate in the treatment group relative to the control during the program period. Importantly and consistent with our empirical strategy, we also do not observe statistically significant differential changes in the private modification rate in the treatment group relative to control group in two quarters preceding the program announcement.

We recall that the program resulted in an absolute increase of $0.17 \%$ in the quarterly permanent modification rate in the treatment group because of the permanent HAMP modifications (Table 1). Combining this relatively large effect of modifications under the program with an estimated small decline in the private permanent modification rate in the treatment group, we get the program effect of about $0.142 \%$ quarterly increase in the permanent modification rate (private or HAMP). In other words, one program modification is associated with about 0.84 more "net” permanent modifications.

We confirm these findings in Figure 2(c), which presents the combined (private and HAMP) permanent modification rates in treatment and control—and more formally in Column (4) of Table 2, where we estimate the overall impact of the program on the rate of permanent modifications (private and HAMP). The estimated coefficient on $T^{*}$ After in Column (4) of Table 2 suggests that the program induced about $0.14 \%$ increase in the quarterly permanent modification rate. ${ }^{16}$ This amounts to about a $35 \%$ increase relative to the pre-program mean modification rate in the treatment group. At this rate, the program would induce about one million additional permanent modifications over its original duration (i.e., end Dec. 2012)— significantly short of the government expectations of three to four million modifications. ${ }^{17}$

At a first glance, the finding of no substantial decline in the intensity of private modifications in the treatment group during the program period may appear surprising. However, note that the program could broadly affect the rate of private renegotiations in two ways. First, in the presence of government incentives, lenders may substitute some of the private modifications with HAMP ones. This crowding-out of private activity with government subsidized one would lead to a decline in the rate of private renegotiations in the treatment group. There may also be a second countervailing force. The program, through its outreach effort, could increase the pool of borrowers in the treatment group who apply for modifications. Since attracting and evaluating

\footnotetext{
${ }^{16}$ We also investigate the relation between incidence of HAMP modification received by a loan and its ownershipi.e., whether loan is securitized into GSE-backed pools (agency loans), is securitized without government guarantees (private-label loans), or is bank-held loans (portfolio loans). We find significant number of HAMP modifications (both trial and permanent) in all ownership categories. These results suggest that, consistent with one of its objectives, HAMP did enhance modification activity on securitized loans.

${ }^{17}$ We arrive at about one million additional permanent modifications induced by the program, assuming that our estimates are valid for the entire stock of 45 million potentially eligible loans for the program in the U.S. This involves applying the same estimate for potentially eligible loans that are not covered in our data and projecting the same rate from the end of our sample period until the end of the program period. Notably, our estimated number of HAMP modifications is very close to the actual program modifications released by the administration in 2013 . This fact lends credibility to representativeness of our sample.
} 
potential borrowers for a modification is costly, it may be profitable for banks to offer a private modification to some applicants who, upon evaluation, did not qualify for a permanent HAMP modification. ${ }^{18}$ Consequently--to the extent that some of the additional applicants who did not receive a HAMP modification could end up getting a private one--the program could also positively impact the intensity of private modifications in the treatment group. The evidence in the data is consistent with the second force largely outweighing the first effect.

\section{V.B Impact on Intensive Margin: Contract Terms and Redefault Rates}

In this section we evaluate the changes on the intensive margin-that is, on the type and effectiveness of modification offered, conditional on the loan receiving a modification. Lenders can change more than one dimension of the contract term when they renegotiate a loan. For example, a lender may offer an interest rate reduction on the loan, as well as writing down the principal. We focus on the key categories of such changes, evaluating the change in the rates of these modification types around the program. We also examine the impact of the program on the rate of default of renegotiated loans ("redefault rate"), a commonly used metric to evaluate the effectiveness of renegotiations (see Haughwout et al. 2010).

Table 3 follows a specification similar to the main one, with the analysis confined to modified loans. The outcome variable measures the type of contract changes in both HAMP and private modifications after the passage of the program. Accordingly, the $T^{*} A f t e r$ interaction term in the present context captures the change in the contract terms associated with both private and HAMP permanent modification in the treatment group relative to the control group. The results in Columns (1)-(4) show that overall permanent modifications in the treatment group became less aggressive relative to ones in the control after the program introduction. The incidence of more aggressive tools like rate reduction, term extension, and principal reduction decrease $(10 \%$, $8 \%$, and $2 \%$, respectively), while the incidence of less-aggressive tools, like capitalization of unpaid interest in the principal amount due, increases (by 9\%).

These estimates reflect differences in tools used for private and program modifications in the treatment group relative to those used for private modifications in the control group. To better understand the change in composition of modification tools, in unreported results we also separately consider the permanent private modifications and HAMP modifications. We observe that servicers offered more comprehensive modification terms for renegotiations done under HAMP. There is a significantly higher incidence of rate reductions observed on HAMP modifications relative to the private permanent modifications in the treatment group (55\% higher). This pattern is consistent with the program requiring participating servicers to make

\footnotetext{
${ }^{18}$ Servicers may have been willing to ex-ante spend resources on borrowers to learn about their program eligibility even if they know that a sizeable proportion of these borrowers would not qualify for the program once necessary information had been collected. This investment may have positive expected value for servicers, with program benefits earned on qualifying borrowers compensating servicers for overall costs incurred on evaluating borrowers.
} 
mortgages more affordable for borrowers with economic hardship and facing imminent default. The incidence of term extensions and principal write-downs is also higher for HAMP modifications, but the magnitudes are smaller (27\% and 3\%, respectively). Thus, although HAMP modifications appear to be more aggressive in terms of concessions offered to the borrower, the fact that overall less aggressive tools were used in the treatment group relative to the control group suggests that concurrently private permanent modifications performed in the treatment group became less aggressive after the program's introduction.

Next, we study the change in re-defaults on modified loans around program implementation. Column (5) of Table 3 uses an indicator of whether or not a modified mortgage redefaults within six months of renegotiation as the dependent variable. Our specification is similar to the main one, with the sample confined to modified loans. There is a significant downward trend in redefault rates for both treatment and control group loans over time. More importantly, Column (5) shows that the program did not significantly affect average redefault rates in the treatment group relative to the control. In particular, the estimated program effect implies a small $0.3 \%$ reduction in redefault rate compared to about $24 \%$ redefault rate in the preprogram period.

To better understand these results, in unreported tests, we evaluate the redefaults separately for private and HAMP modifications. We find that the redefault rate of HAMPmodified loans is significantly lower than that of private permanent modified loans in the treatment group (5\% in absolute and $25 \%$ in relative terms). This pattern is consistent with our evidence that HAMP modifications appear to be more aggressive in terms of concessions offered to borrowers. ${ }^{19}$

Given that we find no significant change in redefault rate in the treatment group relative to control group, we conclude that the increase in efficiency (as measured by the redefault rate) due to HAMP modifications is entirely offset by concurrent reduction in efficiency on private permanent modifications in the treatment group. This inference is confirmed by the fact that less aggressive modifications were used for private modifications in the treatment group. ${ }^{20}$ Notably, finding no significant change in the overall effectiveness of modifications in the treatment group does not imply that the program did not have an effect on other economic outcomes. As we already showed in Section V.A, the program did induce a substantial increase in the overall rate of modifications in the treatment group (i.e., due to expansion on the extensive margin).

\footnotetext{
${ }^{19}$ We also note that borrowers whose loans received a program modification could receive up to $\$ 1000$ dollars per year (up to 5 years) if their loans remain current on payments. These incentive payments could also contribute to relatively lower redefault rate on HAMP modifications relative to private ones.

${ }^{20}$ Note that these effects, in part, could reflect servicers channeling better loans (on unobservables) to be modified under the program. The reason is that incentive payments under the program were higher if a loan did not redefault after a modification. This change in composition of loans modified under the program versus outside it could also partly explain an adverse impact of the program on the effectiveness of private modifications in the treatment group.
} 


\section{V.C.1 Foreclosure Rates}

We now examine the impact HAMP had on the outcome it was designed to ultimately affect - that is, the rate at which loans are foreclosed. Table 4 assesses HAMP's effectiveness in preventing foreclosures by examining how the rate at which a loan was foreclosed in a given quarter varies across the treatment and control groups. The coefficient of interest in these regressions is $T^{*} A f t e r$.

The results indicate that there was a decrease in the rate of completed foreclosures in the treatment group during the program period. Among all the loans, we observe a $0.094 \%$ decrease in the quarterly foreclosure rate (about 12\% lower than the foreclosure rate in the control group during the program period). ${ }^{21}$ This implies a decrease of $0.37 \%$ in the annual foreclosure rate, which would translate into about 600,000 fewer foreclosures among eligible loans over the original duration of the program (i.e., through December 2012). ${ }^{22}$ As Column (3) indicates, the estimated reduction in the foreclosure rate is robust to inclusion of state fixed effects for the location of the property backing the mortgage.

In the next three columns we conduct an alternative test in which we evaluate the change in foreclosure rates for delinquent loans instead of using all the loans. As explained earlier, we prefer to do our analysis on all loans, because delinquency status of a loan is itself an endogenous variable that could be affected by HAMP (also further discussed in Section V.C.2). With this caveat in mind, the test does give us an assessment of how foreclosure rates change on distressed loans. Among delinquent loans we observe about a $1.6 \%$ absolute reduction in the quarterly foreclosure rate. Notably, Column (6) shows that the estimated reduction in the foreclosure rate among delinquent loans is also robust to inclusion of the state fixed effects for the location of the property backing the mortgage. ${ }^{23}$

These estimates capture the impact of the program on foreclosure rates due to the combined effect of trial and permanent HAMP modifications, changes in the number and

\footnotetext{
${ }^{21}$ Alternatively, this estimate represents a $40 \%$ relative decrease with respect to the mean foreclosure rate in the treatment group prior to the program. Note that the relative reduction in foreclosure rate relative to the control group during the program period is smaller than this estimate because foreclosure rates have been trending upward.

${ }^{22}$ We arrive at 600,000 fewer foreclosures induced by the program, assuming that our estimates are valid for the entire stock of 45 million potentially eligible loans for the program in the United States. This involves applying the same estimate for potentially eligible loans that are not covered in our data.

${ }^{23}$ To further explore the timing of these effects, we re-estimate the specification in Column (3) of Table 4 where we replace the After dummy with quarterly dummies and their interactions with the treatment dummy (the excluded category includes observations from 2008:Q3). Consistent with our earlier results, we find the program resulted in a meaningful decline in the foreclosure rate in the treatment relative to the control group with this effect being the most pronounced during the first two years of the program (2009 and 2010).
} 
composition of private modifications, and the program's impact on other servicing actions and outcomes that may impact foreclosure rates. In Section VI.A.2 we provide evidence that suggests that it is the increase in permanent modification rate due to the program that is primarily driving the reduction in the foreclosure rate. However, keeping the exact driving channel aside for now, our estimates in Tables 1, 2 and 4 imply that one program modification is associated with about 0.84 more net permanent modifications and about 0.55 fewer foreclosures.

We also note that these estimates are obtained for our sample period corresponding to the first 3 years of the program (2009:Q2 till 2012:Q2). It is possible that a part of the estimated decline in foreclosure rates may be temporary. For instance, servicers may just be delaying some foreclosures while the program is being implemented. Nevertheless, we note that even if part of the reduction in foreclosure rates due to HAMP was temporary and confined to our sample period, such a reduction may have some social benefits by spreading the incidence of foreclosures over a longer horizon (see Mian, Sufi, and Trebbi 2015).

\section{V.C.2 Delinquency Rates}

An important concern regarding mortgage modification programs is that they may induce borrowers, who would otherwise continue making payments, to default in order to increase their chances of receiving help (see Mayer et al. 2014). We now examine whether HAMP induced

such strategic behavior on the part of borrowers by evaluating the propensity of borrowers to become delinquent in order to benefit from reduced debt payments under the program.

To investigate such effects, we estimate a specification capturing the transition rate of a loan payment status from being current to 60 days delinquent. We find no evidence that the program resulted in a significant change in default rate in the treatment group relative to the control one in any quarter during the program period. Consistent with our empirical strategy, we also find no statistically significant differential changes in the default rate in the treatment group relative to control group prior to the program announcement (see Online Appendix A4 for more details).

This evidence suggests that strategic behavior of borrowers may have been constrained by HAMP. These results seem sensible and may provide guidance for designing large-scale renegotiation programs in the future. In particular, HAMP guidelines contained multiple eligibility requirements that required borrowers to produce documentation of their economic hardship and danger of imminent default. The program also features an evaluation trial period prior to permanently changing the contract with the borrower. Moreover, the program provides additional compensation to servicers for modifying the loans that were current on their payments. Thus, our results suggest that loan modification programs could limit strategic behavior by 
introducing similar extensive screening related to its eligibility criteria and its design of incentives for servicers. $^{24}$

\section{Extensions}

\section{VI.A Alternative Identification Strategies}

\section{VI.A.1 Strategy II: Exploiting Loan Amount Eligibility Cutoff among Owner Occupied Loans}

One potential criticism of our empirical strategy is that even though the control and treatment loans are comparable on observable dimensions, the two sets of loans might still differ on unobservables because they differ on owner-occupancy status. We now refine our empirical strategy to provide additional support for the findings derived using treatment and control groups that are formed based on owner-occupancy status.

This alternative empirical strategy (called Strategy II) exploits program eligibility criteria based on loan amount within the group of loans for owner-occupied properties. Among borrowers with properties that are owner-occupied during program implementation, those with mortgages with outstanding balances above $\$ 729,750$ are ineligible for the program. ${ }^{25}$ Therefore, we use these loans to construct the control group to measure the counterfactual level of renegotiations for mortgages with balances just below $\$ 729,750$ (treatment group) in the absence of HAMP.

Notably, relative to our main empirical strategy, this alternative strategy is likely to consist of loans in the control group that match better with those in the treatment group. The reason is that both groups consist of loans for owner-occupied properties with relatively similar balances. Specifically, similar to our main empirical specification, we estimate:

$$
Y_{\mathrm{it}}=\alpha+\beta \times \mathrm{T}_{\mathrm{i}}+\gamma \times \mathrm{T}_{\mathrm{i}} * 1(\text { After })_{\mathrm{it}}+X_{\mathrm{it}} \delta+\varepsilon_{\mathrm{it}},
$$

where $T$ takes a value of 1 for loans in the treatment group and 0 for the loans in the control group. After takes a value of 1 for the quarters after 2009:Q1 and is 0 otherwise. Loans for owner-occupied properties whose amount outstanding is below $\$ 729,750$ prior to the date of announcement of the program (March 2009) take a value of $T=1$, while loans for owneroccupied properties with the balance above this threshold take the value of $T=0$. To make the

\footnotetext{
${ }^{24}$ These findings are in contrast to strategic behavior induced by simpler modification programs. Mayer et al. (2014) show that the simple modification program by Countrywide Financial Corporation led to significant strategic defaults. Unlike HAMP, the Countrywide modification program did not employ extensive screening of borrowers.

${ }^{25}$ The \$729,750 figure equals the temporarily increased maximum conforming loan eligibility limit for high-cost areas that was incorporated into the 2008 economic stimulus package. The new jumbo-conforming program was adopted by Fannie Mae and Freddie Mac, effective April 1, 2008, until December 31, 2010. Because the vast majority of loans in our sample were originated before April 2008, this loan limit had no particular meaning during their origination process (e.g., all loans in close range of this limit were not eligible for conforming loan status).
} 
loans in the treatment and control groups in the second strategy closely comparable, we restrict attention to loans that are within $\$ 100,000$ of the threshold. The vector Xit contains a set of borrower, loan, and regional characteristics and includes After. As before, we estimate these regressions on all mortgages and employ the same outcome variables.

Table 5A confirms that loans in the control group are very similar to those in the treatment group in terms of their observable characteristics. These patterns are also visible in kernel densities of FICO credit score, LTV, and interest rates for the borrowers in the treatment and control groups and the evolution of these observables over time (Online Appendix A5 and A6).

Figure 3(a) presents the fraction of loans that enter the trial and permanent HAMP modifications for the first time in a given month in the control and treatment groups as defined by this alternative strategy. The patterns in the plots suggest inferences similar to those obtained with our main empirical strategy.

Table 5B shows that, consistent with results in Table 2, there is no evidence that the program resulted in a substantial decline of the rate of private modifications in the treatment group (Column 1). In line with the results based on our first empirical strategy, there is a small decrease in the quarterly rate of permanent private modifications (by about $0.03 \%$ ). Column (2) confirms this inference by estimating the overall impact of the program on the rate of permanent modifications (private and HAMP together). The quarterly rate of permanent modifications in the treatment group increases by about $0.21 \%$ relative to the control one (about a $30 \%$ increase relative to the mean permanent modification rate in the treatment group). These findings are also visible in Figure 3(c). These results are consistent with our previous findings of a significant positive effect of the program on the extensive margin.

Column (3) presents the results on redefault for the alternative identification strategy. Consistent with our previous results, we find no change in the overall efficiency of modifications in the treatment group relative to the control after the program was implemented.

Finally, Columns (4) and (5) present the foreclosure results for the alternative strategy. Again, we find qualitatively similar evidence as before: the program reduced the number of foreclosures in the treatment group relative to that of the control. As Column (4) shows the estimated decline in the quarterly foreclosure rate equals $0.14 \%$ per quarter $(-2.19 \%$ among delinquent loans).

We note that we have classified borrowers as potentially in the treatment or control group based on their loan status prior to the program announcement. A borrower in the control group with a loan balance above the $\$ 729,750$ threshold may strategically become eligible for HAMP if the borrower pays down the loan's principal over time. There are several reasons why this is not 
likely. One, we note that very few loans in our data cross the balance threshold in our program period from the control group to the treatment group. Two, most of these loans appear to cross the threshold because of the mechanical amortization schedule implied by their mortgage payments before the program announcement. Three, we classify borrowers as potentially in the treatment or control group based on their loan status prior to the program announcement, which circumvents the issue of potential manipulation of loan balance by borrowers to become eligible for the program (biasing against finding program effects).

We conclude this section by noting that the estimates obtained in this section imply effects that are quantitatively very similar to those obtained using Strategy I (exploiting the variation in owner-occupancy status). In particular, the estimates based on Strategy I (Tables 1, 2 , and 4) imply that one additional program modification is associated with about 0.84 more net permanent modifications and 0.55 fewer foreclosures. In comparison, the estimates based on Strategy II (Table 5) imply that one additional program modification is associated with 0.87 more net permanent modifications and 0.58 fewer foreclosures. ${ }^{26}$ The similarity in our estimates from two empirical strategies that exploit very different sources of variation comforts us of the soundness of our empirical design.

\section{VI.A.2 Strategy III: Exploiting NPV Eligibility Cutoff}

So far both our empirical strategies relied on comparing outcomes of loans that are potentially eligible for the program to those that are ineligible. This helps us identify the overall impact of the program through its effect on multiple aspects - i.e., through its effect on applications, trial modifications, permanent modifications, as well as private modifications. We now augment this analysis by focusing on a subset of truly eligible loans that get a permanent modification under the program and comparing the outcomes on these loans to those that narrowly miss becoming eligible for the program. This allows us to isolate the impact of the permanent program modifications on the foreclosure rate.

We exploit the program rules to generate plausibly exogenous variation in the incidence of program modification across a set of loans. In particular, we take advantage of the program eligibility requirement that requires the mortgage to pass the NPV test. In order to receive a modification under the program, it has to be the case that NPV of providing a permanent HAMP modification for the lenders/investors relative to the case of no modification is positive. ${ }^{27}$ To

\footnotetext{
${ }^{26}$ Our estimates in Table 5 suggest that the program led to an increase in quarterly program modification rate by $0.24 \%$, amounting to a $0.21 \%$ net increase in the permanent modification rate after netting out slight substitution of private modifications with HAMP ones $(0.87=0.21 / 0.24)$, and about $0.14 \%$ quarterly decline in the foreclosure rate $(0.58=0.14 / 0.24)$.

${ }^{27}$ The test was jointly developed by the Treasury and the GSEs, using an econometric model fitted to historical data to estimate the probabilities of cure and of default as a function of a set of observable loan and borrower characteristics. In particular, these characteristics included: loan terms, mark-to-market LTV, current FICO scores, monthly income, loan performance status, etc. The model yielded a set of parameters to be used in estimating cure 
conduct this analysis, we hand match a random sample from our data with the U.S. Treasury data on HAMP applications. ${ }^{28}$ Specific to our purpose, the matched data contains information on the numerical values of the NPV resulting from a permanent HAMP modification. It is computed as the difference between the present discounted values of repayments in case of a HAMP modification and the present discounted value of repayments in case of no modification.

It is worth noting that our analysis compares decisions across different servicers. Importantly, however, there is no heterogeneity in the usage of NPV model across servicers. They had no discretion about what variables to input into the NPV model, nor what parameters to use, nor were they allowed to augment the resulting scores on the basis of any other additional information. Each servicer had to follow the exact specifications of the test established by the Treasury. The Treasury also conducted quarterly audits to make sure output from the servicer NPV model exactly matched those from the Treasury's model. In return for following the standardized process, the servicers were granted "safe harbor" from lawsuits by investors unwilling to modify loans on HAMP terms.

To ensure that we have a tight set of comparable loans, we assess applications that satisfied all other program eligibility criteria but differed on the final NPV test values, with these values all in the vicinity of zero. For that purpose, we focus on a tight set of test values around zero, representing $10 \%$ of the overall realized range of the NPV test. Among these loans, the treatment group is the set with NPV values greater than zero, while those with negative NPV values form the control group. Moreover, in line with program rules, positive NPV loans did receive a permanent HAMP modification while those with negative values did not. We then track the outcomes in the two groups over time to assess the impact of permanent program modification. The assumption underlying this assessment is that, conditional on observables, the distribution of borrower quality around NPV test value of zero is smooth.

The average NPV test value of the treatment group is around \$5,000 while that of the control group is around $-\$ 4,200$ (compared to $\$ 141,158$ to $-\$ 112,865$ range in the overall data). Importantly, both groups of loans have similar interest rates and origination LTV ratios (see Online Appendix A7). The borrowers in the treatment group have somewhat lower FICO credit scores relative to the control group (671 versus 680), which if anything should make it harder for us to establish the adverse effect of treatment (HAMP modification) on the incidence of

and default probabilities in two scenarios - one for a HAMP modified loans and another for a loan that is left unmodified. These probabilities were further augmented by a set of assumptions about HAMP incentive payoffs, timing of cash flows, and recovery rates to generate an NPV estimate for each of the scenarios. The model is described in detail in the HAMP NPV Model Documentation manual, available at: https://www.hmpadmin.com/portal/programs/docs/hamp_servicer/BaseNPVModelDocumentationv6.pdf

${ }^{28}$ Note that there are no common identifiers between the two datasets. As a result, time-consuming, hand matching had to be done. This matching was based on several variables such as data of application, property value, loan terms and region of the mortgage. Since there are several million applications, and this is a robustness test, we chose to do this exercise for a random sample of $1 \%$ of these applications. 
foreclosure. This similarity in the two groups is not just confined to the averages but also to the kernel densities of these variables (see Online Appendix A8).

In the first four columns of Table 6 we examine the effect of permanent HAMP modification on foreclosure rate by analyzing the evolution of foreclosures in treatment group relative to the control group. We focus on one and three year horizon following the NPV test date. Consistent with our prior evidence, we find that receiving a program modification reduces the foreclosure rate with the effect ranging from 12 percentage points reduction in probability of foreclosure at one year horizon to 28 percent at three year horizon. Since all the loans in the treatment group receive a program modification, these estimates imply that one permanent program modification is associated with about 0.3 fewer foreclosures over the three year horizon. These inferences are robust to alternative specifications used in the paper. In particular, we obtain similar magnitudes when controlling flexibly for NPV test values in these regressions. The magnitudes in such specifications range from 12 to 12.5 percentage points reduction in probability of foreclosure at one year and 28 to 28.2 percentage points at three year horizon (always significant at $1 \%$ level).

Our previous findings (Section V) imply that one permanent program modification is associated with about 0.55 fewer foreclosures over the same horizon. There are several potential reasons for the difference in these magnitudes. First, notice that in order to be close to the control group on every dimension, by construction, we have restricted the treatment group to be loans that have NPV values that are close to zero. Thus, our effects are likely a lower bound on the true effect of a permanent HAMP modification on foreclosures in the entire sample used by our earlier strategies. Second, as mentioned earlier, in contrast to our earlier tests that identified the overall impact of the program through its effect on multiple aspects, Strategy III isolates only the impact of the program permanent modifications on foreclosure rate. Regardless, despite the expected differences in the magnitudes across our current and earlier estimates, Strategy III reinforces our prior findings - there is a meaningful reduction in the foreclosure rate due to the program. Moreover, these results suggest that substantial part of this reduction can be attributed to the program-induced permanent modifications.

Finally, we note that these estimates are consistent with simple back of the envelope calculations that take into account the fact that many modified loans re-default after modification and that some delinquent loans become non-delinquent even without modifications (i.e., are selfcured). In particular, our estimate of re-defaults on loans modified under HAMP is around 20\%. This implies that about $20 \%$ of loans modified under the program would end up in foreclosure. Moreover, based on prior work (e.g., Piskorski et al., 2010), self-cure rates are around 40-50\%. Thus, a delinquent loan, which does not self-cure will be foreclosed with 50-60\% probability. The overall treatment effect of the program modifications on foreclosures would then be around $30-40 \%$ [i.e., (50-20)\% or (60-20)\%]. This is quite comparable to estimates obtained in Strategy 
3 (about 30\%) which estimates the effects of permanent modification on foreclosures. These are also in the same ballpark as Strategy I and II (about 55\%) which are likely larger since these tests estimate the change in foreclosures as a result of variety of actions under the program that include permanent modifications and trial modifications.

\section{A.3 Strategy IV: Exploiting Change in Program Eligibility in 2012:Q3}

We now provide further evidence to address concerns about the validity of Strategy I. We exploit a change in the program rule that made a subset of non-owner occupied loans - i.e., our control group in Strategy I -- to be eligible for the program. From June 2012, HAMP's owneroccupancy eligibility criteria were relaxed under the HAMP Tier 2 program. In particular, the change allowed HAMP modifications to be offered to some non-owner occupied residential mortgages -- those financing properties occupied by a tenant or properties available for rent on a year-round basis. These loans, like other mortgages financing non-owner occupied properties, were ineligible for the program prior to this date. This presents us with a unique opportunity to assess what the program effect would be in the control group of loans, were they to become eligible for the program. If the control group indeed is well matched with treatment, we would expect similar effects on the set of newly eligible loans. ${ }^{29}$

We start by investigating the modification rate in the newly eligible loans from the start of program implementation for these loans (Q3 2012). Using aggregate data from the U.S. Treasury we find a broadly similar pattern of program modification rate in the aggregate sample of non-owner occupant loans that became eligible during the sample period as we do in the sample of owner occupant loans (the original treatment group). This, of course, is not rigorous evidence that the effects of the program in the newly set of eligible loans was similar to that in the treatment group. Next, we use micro data to better assess this issue.

In particular, we study the impact of program modification on foreclosure rate among newly eligible loans. To form a reasonable counterfactual for newly eligible loans, we follow a similar approach to Strategy III that is discussed in Section VI.A.2. We use the sample of our data hand matched with the random sample of HAMP applications related to HAMP Tier 2 program, starting after June 2012. As before, we focus on the applications that passed all other program eligibility criteria and received NPV test values in the vicinity of zero (i.e., in the + or -

\footnotetext{
${ }^{29}$ We are grateful to Ali Hortaçsu, for suggesting this test. Note that one approach to conducting such a test is to maintain the empirical design of Strategy I -- i.e., contrast owner occupant loans to non-occupant ones around program implementation - and additionally assess differential change in the small fraction of newly eligible loans in the control group around June 2012. Unfortunately, data limitations prevent us from performing such an analysis. In particular, doing so within the design of Strategy I requires information on whether a given loan with non-owner occupied status is for rental or tenant-occupied property before the start of the program (March 2009). However, U.S. Treasury data only provides such loan level information from mid-2012. This makes it infeasible to follow such an approach. Moreover, the change in program rules impacted only a small fraction of the control group, since the majority of loans financing non-owner occupied properties (e.g., second homes) were still ineligible for the program. As a result, the power of tests following such an approach would also be limited.
} 
$10 \%$ of the overall range of the NPV test). Among these loans, the treatment group is the set with NPV value greater than zero, while those with negative NPV value form the control group. We first verify that, in line with program rules, loans with positive NPV values did all receive a permanent HAMP modification while those with negative values did not. We then track the outcomes in the two groups over time to assess the impact of permanent program modification. As before, the assumption underlying this assessment is that, conditional on observables, the distribution of borrower quality around realized NPV test value of zero is smooth.

On average, the loans in both the groups are quite comparable on dimensions of FICO, LTV and interest rates (see Online Appendix A7). In the last two columns of Table 6 we examine the effect of an additional HAMP modification on the foreclosure rate. Note that, we make this assessment over the horizon of one year since we are constrained by data availability from Treasury. Consistent with our evidence related to Strategy I, we do indeed find that receiving a program modification meaningfully reduces the foreclosure rate. The magnitudes imply a reduction of about $8 \%$ in absolute terms over the period of one year. This effect is comparable with a $12 \%$ estimated reduction in the foreclosure rate due to the program modification over the same horizon, estimated using Strategy I on loans in the HAMP Tier 1 program.

Overall, this test provides further support validating our main empirical strategy. We observe a broadly similar program modification rate in the aggregate sample of non-owner occupant loans that became eligible during the sample period as we do in the sample of owner occupant loans. Moreover, these newly eligible loans see reduction in foreclosure rate that is also consistent with those estimated in the owner occupant loans by our first empirical strategy.

\section{VI.B Potential Bias due to Reallocation}

Our estimated treatment effects may be biased because servicers may use up some of their resources for conducting HAMP modifications in the treatment group at the expense of modifications in the control group, given the program incentives. This channel, if operational, could inflate the program effect since our estimate in the treatment group is measured relative to the control group, which would concurrently see lower modification rates due to reallocation of resources by servicers. We now investigate if there is evidence for this concern.

First, we examine if there are differential trends in the control group around the program implementation. The thought experiment is that reallocation of resources by servicers from the control group should change the intensity of modifications in this set of loans after the program is implemented. We use the baseline regression in Table 2, analyzing the time trend in modification activity in the control group of loans around the program implementation. We find no evidence for this conjecture. The inferences are similar when we do a quarter-by-quarter analysis instead (unreported). 
Second, we compare the evolution of modifications in the control group, for HAMPparticipating servicers in our sample, to modifications in the group of loans that would have qualified to be in the control group based on program criteria, had their servicers not opted out of HAMP. As explained in Section II, these are mainly servicers sponsored by foreign underwriters. If servicers implementing modifications under HAMP do reallocate resources from the control group, we should expect a difference in modification activity after the program implementation for loans handled by these servicers relative to similar loans being handled by non-participating servicers. We use the baseline regression in Table 2, analyzing the modification activity only in the control group of loans. Differences in the modification activity between the two sets of servicers after the program implementation are captured by the interaction term After*Foreign, where Foreign is an indicator variable which takes a value 1 if a loan belongs to deals underwritten by foreign underwriter whose servicers opted out of the program and 0 otherwise. Online Appendix A9 shows that there is no such difference.

We also investigate the relative change in private modification rate between treatment and control groups formed based on occupancy status for servicers that did not participate in the program. Focusing on these servicers allows us to investigate if the evolution of outcomes in the treatment and control groups is similar in the absence of the program. Indeed, the modification rates of both treatment and control loans handled by such servicers shows the same difference before and after the program (see Online Appendix A9).

Finally, we assess if the treatment effect changes with a higher proportion of treatment group loans in the portfolio of the servicer. Under the alternative being tested, a higher proportion of treatment group loans should result in greater reallocation of resources by servicers from the control group after the program is implemented, thereby changing the treatment effect differentially. To test this, we employ our baseline specification from Table 2 but also include an interaction of $T$ with a variable Share, which is the proportion of treatment group loans in the portfolio of that servicer. In unreported tests, we find no evidence for such a scenario.

The analysis in this section suggests that servicers may not have shifted resources from servicing loans in the control group to the treatment group. These results also suggest that the servicing technology is such that the marginal cost of offering an additional modification for a given servicer is roughly constant. This is likely to be the case if the main costs of performing private modifications were mostly of the fixed type, such as setting infrastructure. ${ }^{30}$ Under this scenario, servicers would simply modify more loans in the treatment group as a result of the program subsidies, leaving their operations in the control group unchanged.

\footnotetext{
${ }^{30}$ This is not the only possible servicing technology. Another possible technology could be that marginal cost of modifying an additional loan is increasing in the total number of modifications. In such a scenario, one would expect servicers to reduce their modifications in the control group because the marginal cost of modifying loans would increase as more renegotiations are performed in the treatment group due to program subsidies.
} 
Combining the results of this section with those we found in Section V paints a picture that is consistent with this inference. Servicers modified more loans in the treatment group-with the more promising candidates for modifications channeled under HAMP to take advantage of program incentive payments-leaving modifications in the control group relatively unchanged.

\section{The Role of Servicers}

We have found that the take-up rate- that is, the number of trial modifications being granted and the conversion rate of trial modifications to permanent modifications - under HAMP was significantly lower compared with policy makers' expectations. Although it is hard to know what the optimal response to the program should have been, we now exploit heterogeneity in response across servicers to try to understand some of the potential barriers to program implementation.

The program's effect on the extensive margin is not uniform across servicers in our sample. There is significant variation in the rate of trial and permanent HAMP modifications across servicers, with some servicers modifying at a rate that is more than four times the rate of others. Importantly, this variation cannot be accounted for by differences in contract, borrower, or regional characteristics of mortgages across servicers. To illustrate this, Figure 4(a) plots the average quarterly trial and permanent HAMP modification rates across the sixteen main servicing entities in our sample. These servicer-specific rates are obtained based on servicer fixed effects from a specification investigating how the likelihood of receiving a trial or a permanent modification under the program relates to observables on a given loan in the treatment group (see Online Appendix A3). The quarterly rates of trial HAMP modifications vary from as little as $0.07 \%$ to almost $0.85 \%$ across servicers. Similarly, the quarterly rates of permanent modifications vary substantially across servicers, from about $0.04 \%$ to about $0.6 \%$. Together, these results imply substantial variation in the conversion rates from trial modifications to permanent modifications across servicers (from $25 \%$ to $75 \%$ ).

Interestingly, there was similar heterogeneity in the rate of private modifications offered across these servicing entities in the pre-program period. Again, this variation cannot be accounted for by differences in contract, borrower, or regional characteristics of mortgages across servicers. This is illustrated in Figure 4(b), which plots the average quarterly permanent private modification rates across the servicing entities in our sample. These servicer-specific preprogram rates are obtained from servicer fixed effects in a regression similar to one in Online Appendix A3, but estimated on pre-program data. The pre-HAMP quarterly rates of permanent private modifications vary substantially across these servicing entities (from less than $0.04 \%$ to $1.4 \%)$.

Table 7A investigates whether there is a relation between renegotiation intensity of servicers in the pre-program period and the rate of permanent modifications induced by the program across 
these entities. To do so we first construct an indicator variable, High Experience, that takes a value of 1 for servicers that are above the median in terms of renegotiation intensity in the preprogram period, and 0 otherwise. The servicer-specific renegotiation intensity in the pre-program period is obtained as in Figure 4(b).

We start by using a specification using loans in the treatment group (as defined by Strategy I), where the dependent variable takes the value of 1 if a loan has received a given HAMP modification and 0 otherwise. Columns (1) and (2) (Columns (3) and (4)) of Table 7A show that loans serviced by servicers that did more renegotiations in the pre-program period are much more likely to receive a trial (permanent) HAMP modification: the corresponding likelihood is bigger by about $2 \%(1.82 \%)$. These are large effects, since they suggest an increase of about $50 \%$ (103\%) relative to the overall mean trial (permanent) HAMP modification rate for low-experience servicers in our sample period. It is worth reiterating that in these specifications we control for all the observable borrower and collateral characteristics (FICO, LTV, interest rates), loan ownership status (securitized or bank held), and for geography (state fixed effects).

We further assess the robustness of this finding by restricting our attention to treatment loans in California and Florida, respectively. Focusing on loans in a specific state allows us to better control for local economic conditions and variation in state laws. Moreover, we also account for regional effects within these states by including zip code fixed effects corresponding to property location in these specifications. The results are presented in Columns (5) and (6) of Table 7A, where the standard errors are clustered at the zip code level. Again, even with more refined controls for geography we find that servicers with high pre-program renegotiation experience perform many more permanent HAMP modifications. Strikingly, the permanent HAMP modification rate among loans in California (Florida) during our sample period is about 4.4\% (3.2\%) higher for high-experience servicers.

Finally, as another robustness check, we estimate the specification restricting our attention to treatment loans classified according to Strategy II. Recall that this sample consists of better-quality mortgages given to owner-occupants with similar loan balances. Consistent with our earlier results, Column (7) shows that high-experience servicers are much more likely to offer permanent HAMP modification: the corresponding likelihood is higher by more than 3\% in absolute terms. ${ }^{31}$ We find similar effects if we cluster at the level of servicers in the regressions that are presented (unreported for brevity). Overall, we find that persistent lower renegotiation activity of some servicers-both before and during the program-cannot be accounted by the heterogeneity in observable characteristics of loans in their servicing portfolios. ${ }^{32}$

\footnotetext{
${ }^{31}$ We also estimated specifications in Columns (5)-(7) of Table 7A for trial HAMP modifications. The findings and inferences are similar to those for permanent modifications (unreported for brevity).

${ }^{32}$ We also note that each of the servicers in our sample services significant number of loans both issued with and without government guarantees (e.g., on average the high experience servicers have around $50 \%$ loans issued with
} 
Although contract, borrower, and regional characteristics of mortgages are important determinants of renegotiation activity of a servicer, ${ }^{33}$ the differential and persistent patterns of renegotiation across servicers cannot be accounted for by these factors. Another possibility that could explain this relates to the organizational capability of the servicers. Organizational factors, such as the quality of the workforce, incentives, and technology, have been found to be responsible for differences in productivity across manufacturing firms (Syverson 2011). Recall that the program requires servicers to verify numerous eligibility criteria regarding the applicant status prior to offering modification. To do this, servicers have to employ appropriate infrastructure and sufficiently trained staff. Thus, we evaluate whether such organizational differences are related with renegotiation experience of servicers.

Table 7B relates servicer organizational characteristics with pre-program renegotiation experience and find significant relationships between several variables. We collect information on servicers' organizational attributes around the introduction of the program from residential mortgage servicer reports generated by the three rating agencies (Standard \& Poor's, Moody's, and Fitch). We aggregate servicers affiliated with the same institution - the level at which many of these servicer reports are available- to conduct this analysis. In Column (1), the number of full-time servicing staff is positively correlated with the intensity of renegotiations conducted by the servicer in the pre-program period. Column (2) confirms that servicers that conducted more renegotiations did have less-constrained staff, as measured by loans per full-time employee. Next, in Column (3), we find that servicers with more renegotiation experience also are the ones who devote more hours to training their employees--a proxy for the quality of the servicing staff. Finally, in Columns (4) and (5) we find that servicers who are more efficient in handling the phone queries - as proxied by the lower percentage of calls dropped and the smaller average call holding time-also conducted more renegotiations. ${ }^{34}$ (also see Online Appendix A10)

Overall, our analysis provides suggestive evidence that servicers with higher pre-program renegotiation activity appear to have the specialized skills and infrastructure that is conducive to implementing loan workouts. Having acquired these skills and infrastructure before the program, these same servicers then extended more modifications under the program.

government guarantee while the other servicers have around 62\% loans issued with government guarantee). Thus, it is unlikely that the results on high renegotiation activity in the pre-program period persisting into the program period can be explained by some servicers that primarily service (or do not service) GSE loans.

${ }^{33}$ Agarwal et al. (2011) show that servicers renegotiate loans they own at a faster rate relative to similar loans that are securitized. Credit score of the borrower and loan-to-value of the mortgage also matter for renegotiation rates.

${ }^{34}$ We also use the information from U.S. Treasury data on the reasons given by the servicers as to why they did not successfully process an application for a permanent modification. We find that high experience servicers are more likely to refuse modifying loans on the basis of objective criteria such as the borrower's ineligibility or the borrower's failure to make payments under the terms of trial modification ("trial plan default"). In contrast, among low experience servicers, an incomplete application and missing information constitutes the main reason for an inability to offer permanent modification. This evidence suggests that servicers with more loans per employee, less training for staff, and longer wait times for phone calls may have been less effective in collecting information on borrowers and verifying numerous program eligibility criteria. 
We end this section by doing a naive counterfactual computation: we compute what the effect of the program would be if the low-experience servicers were to renegotiate the loans at the same rate as their high-experience counterparts. Since $75 \%$ of the loans are serviced by lowexperience servicers, our estimates imply that HAMP would have induced about $70 \%$ more permanent HAMP modifications, if the loans by low-experience servicers were renegotiated at the same rate as their high-experience counterparts. This would translate into more than 700,000 additional program modifications until its original end date (December 2012). In addition, there would be up to 380,000 more prevented foreclosures, assuming that these additional program modifications would be associated with similar reduction in foreclosure rate as the one implied by our estimates.

\section{Impact of HAMP on House Prices and Other Outcome Variables}

We now explore the impact of the program on house prices and other regional outcome variables. The goal from this exercise is to inform on the effect of debt relief programs such as HAMP, on broader set of economic outcomes when such programs are implemented intensively.

The challenge for using HAMP as an episode to infer such a connection is that, as we have shown, there was a relatively muted response to the program. We circumvent this challenge by using the results from the previous section, and exploiting regional heterogeneity in the share of loans in a region that are serviced by "high-experience" servicers just prior to the program. Because servicer concentration in a region is determined prior to the program and is very persistent in the data, we can explore the effects of HAMP on different economic outcomes using variation in this ex-ante measure of the program exposure. The idea is to compare the economic outcomes in regions that had high concentration of loans serviced by high-experience servicers before the program-and therefore were also regions more likely to receive HAMP modifications - to otherwise similar regions with a low concentration of loans serviced by these servicers. This approach is similar to that used by Mian and Sufi (2010).

\section{VIII.A Empirical Design}

Our empirical strategy of exploring the impact of the program on regional outcome variables relies on zip code data, because we do not have more granular data for variables like house prices. We confine our analysis to zip codes that have at least 250 mortgages in the OCC database, and this leaves us with a sample of about 10,000 zip codes. Imposing this restriction, which allows for reliable estimates, does not change the sample composition much-for instance, the mean share of loans serviced by high-experience servicers in a zip code in the restricted sample is very close to the overall share of these loans in an entire data set ( 25\%).

We first verify that our ex ante measure of regional HAMP exposure based on a share of loans serviced by high-experience servicers in a zip code before the program indeed correlates 
with the subsequent treatment from the program. Notably, servicer concentration in a region is very persistent over time, with around $95 \%$ of loans continuing to have the same servicer that handled these loans at their origination.

Table 8A presents the results of a regression in which the dependent variable is a fraction of modified loans under HAMP in a zip code during 2009:Q2 and 2012:Q4, and the explanatory variable is a fraction of loans serviced by institutions classified as high experience in a zip code as of March 2009 (High Experience Share). Column (1) shows a strong positive association between the fraction of HAMP-modified loans and the share of loans serviced by highexperience servicers in a zip code. A one-standard-deviation increase in the high experience share (about 25\% relative increase) is associated with a $0.43 \%$ absolute increase in the fraction of HAMP-modified loans in a zip code (around a 18\% increase in relative terms with respect to the mean zip code fraction of HAMP-modified loans). This is consistent with our results from the loan-level analysis (Section VI) and demonstrates that zip codes with a larger ex ante measure of the program exposure-a higher share of loans serviced by high-experience servicers as of March 2009—did subsequently receive more treatment ex post (2009:Q2-2012:Q4).

Next, we use share of loans serviced by high experience servicers in a zip code in the preprogram period to generate variation in how intensively the program was implemented. More specifically, we construct such regions by restricting our sample to zip codes in the top quartile (high exposure group) and bottom quartile (low exposure group) in terms of a share of loans in the zip code serviced by high-experience servicers as of March 2009. While these regions provide us with significant variation in program exposure -- and consequently in the intensity of program implementation -- they may differ on several dimensions such as collateral quality being serviced. Accordingly, we focus on zip codes by matching the high and low exposure groups using propensity score. This approach employs a large set of matching covariates, including zip-code-level averages of the FICO score of borrowers, interest rates, LTV, and delinquency rates in the pre-program period (2008:Q3 to 2009:Q1). We end up with 704 zip codes, equally split between high and low exposure groups, after this matching exercise. Notably, the percentage of loans serviced by high experience servicers in a zip code ranges from around $50 \%$ in the high exposure group to $6 \%$ in the low exposure group in this sample.

We next investigate the time series evolution of characteristics of matched high and low exposure zip codes. The mean FICO score, interest rates, LTV, and fraction of loans transitioning from current to 60-day delinquency are close to each other across these groups of zip codes and follow a similar pattern in the pre-program period (see Online Appendix A11). Since the high exposure group has a higher proportion of loans serviced by high-experience servicers, in unreported tests we find that the level of private modifications is higher in this group. Importantly, the difference in private modification rates between the high and low 
exposure zip codes is constant in the pre-program period. This is consistent with evidence shown in Section V.

Columns (2) and (3) of Table 8A reveal that the strong positive association between the fraction of HAMP-modified loans and the share of loans serviced by high-experience servicers in a zip code is also found in the matched sample. A one-standard-deviation increase in the high experience share is associated with about $0.8 \%$ absolute increase in the fraction of HAMPmodified loans in a zip code (about 20\% relative increase with respect to the mean fraction of HAMP-modified loans in this sample).

\section{VIII.B Foreclosures and House Prices}

We now analyze how the quarterly rate of foreclosures varies with program exposure in regions with large differences in how intensively the program was implemented. Our estimates indicate that HAMP resulted in permanent modifications of about $15 \%$ of all delinquent loans. Including trial modifications would increase this to about one third of all delinquent loans. These statistics are almost twice as large in high exposure regions implying that we have enough power at the regional level to detect the effect of HAMP on zip-code foreclosure rate.

We use our matched sample and estimate a regression with change in the zip code quarterly rate of foreclosures between the program and pre-program period as the dependent variable, and High Experience Share as the explanatory variable. Table 8B (Column 1) shows that zip codes with a larger high experience share saw a more decline in the foreclosure rate. The estimates suggest that a one-standard-deviation increase in high-experience share (33\% relative increase) is associated with about $0.08 \%$ decline in a quarterly foreclosure rate (about $15 \%$ decrease relative to the mean foreclosure rate). Column (2) shows that these results are robust to including controls. These results corroborate the loan-level analysis in Section V.

Next, we examine the differences in house price growth in regions classified on the basis of their exposure to the program. Several recent papers argue that foreclosures create downward pressure on house prices (Campbell et al. 2010; Mian, Sufi, and Trebbi 2015). Accordingly, we are interested in examining if regions with more exposure to HAMP—which are also the regions that experienced relative decline in foreclosure rates in the program period-saw an increase in house prices relative to regions with limited program exposure. Again, given the sizeable effect of HAMP on delinquent loans in high exposure areas, our empirical setting should allow us enough statistical power to detect such effects.

We use the matched sample and estimate a regression with a change in the quarterly house price growth between the program and pre-program period as the dependent variable and High Experience Share as the explanatory variable. The estimate in Column (3) of Table 8B indicates that zip codes with a larger high experience share saw an increase in the growth rate of 
house prices. A one-standard-deviation increase in the high-experience share is associated with about a $0.24 \%$ relative increase in the quarterly growth rate of house prices. As Column (4) shows, this estimate is robust to adding zip-code-level controls.

An alternative way to illustrate these findings is to exploit only the differences between high and low exposure regions. Figure 5(a) plots the mean quarterly house price growth in high and low exposure zip codes. The zip-code-level house price data come from CoreLogic. While the difference between low and high exposure zip codes remains relatively stable before the program announcement, the gap between these groups grows from mid-2009. Zip codes with significant exposure to the program saw a meaningful relative increase in house prices after the program's introduction, at least in the near term. Moreover, the increase in the growth rate of house prices in the high exposure group during the program period broadly coincides with the timing and intensity of program modifications, including trial ones (see Figure 2(a)).

It is, of course, possible that part of this house price change reflects a change in the composition of transacted properties due to the relative lower intensity of foreclosure sales in the high exposure zip codes relative to low exposure ones. To assess the robustness of our results to this concern, we repeat this exercise using the CoreLogic house price index, which excludes distressed transactions. Our inferences remain unchanged. Figure 5(b) demonstrates the same results graphically.

\section{VIII.C Delinquencies on Other Consumer Credit and Consumption}

Next, we investigate how HAMP is related to other outcome variables, such as delinquencies on other consumer credit, and durable consumption (auto sales). Figure 5(c) plots the time-series evolution of change in the quarterly delinquency rate on consumer credit in the high and low exposure zip codes. This figure suggests that there was a meaningful relative decline in the delinquency rates of consumer credit in zip codes with high program exposure. Table 8B (Columns (5) and (6)) confirms these results in a regression setting. The estimates in the table suggest that a one-standard-deviation increase in high-experience share in a zip code is associated, on average, with about a $0.24 \%$ decrease in the zip code quarterly delinquency rate on consumer debt in the program period relative to the pre-program period. In additional tests, we separate consumer credit in separate categories such as home equity line of credit and credit cards (unreported for brevity), and find similar significant effects in these categories.

In Figure 5(d), we plot the time-series evolution of growth rates in new auto sales in high and low exposure zip codes. We observe an increase in auto sales growth rate in high exposure zip codes relative to low exposure ones following the program implementation. Table 8B (Columns (7) and (8)) confirms this inference in a regression setting: a one standard deviation in high experience share is associated with about $0.5 \%$ increase in the quarterly auto sales growth. 


\section{VIII.E Instrumental Variables Setting}

We verify the robustness of these findings in the overall sample of zip codes -- not just matched ones--by directly instrumenting for the intensity of HAMP implementation in a region with our measure of ex ante HAMP exposure. Online Appendix A12 shows these results. Consistent with our prior results we find that an increase in program exposure in a region is associated with a relative decline in foreclosures and consumer debt delinquency rates, and an increase in house price and auto purchase growth rates. In particular, we find that a one percent absolute increase in the percentage of modified loans is associated with the reduction in the quarterly foreclosure by $0.03 \%$. This estimate implies that over the original program length (April 2009 till December 2012) an additional program modification in a zip code is associated with about 0.5 fewer foreclosures. Notably, our IV based zip code level estimate of the overall effect of the program on foreclosure rate is broadly in line with our earlier loan level evidence that computes similar effect (Section V.C): one program modification is associated with about 0.55 fewer foreclosures over a comparable horizon.

\section{VIII.D Implications}

Our evidence suggests that mortgage debt relief programs, when used with sufficient intensity, may have a meaningful impact on foreclosure rates, delinquencies on non-targeted consumer debt, house prices, and durable spending. In particular, recall that on average a permanent HAMP modification resulted in about 25\% reduction in payments in our sample, a saving in the order of \$300-\$400 per month. Hence our estimates from Table 8 imply that a onestandard-deviation increase in the high-experience share--which would translate into such reduction of payments for about $20 \%$ more borrowers in relative terms during the program period--would be associated with about $1 \%$ annual increase in house prices, about $1 \%$ annual decrease in consumer debt delinquencies, and about $2 \%$ annual increase in durable spending growth rate. In this respect, this evidence is in line with the recent studies that establish a link between foreclosures house prices, and real economic activity (e.g., Campbell et al. 2010; Mian, Sufi, and Trebbi 2015).

\section{Discussion}

\section{Related Literature}

Our paper is related to the small body of empirical literature that evaluates the impact of government intervention in distressed debt markets. This literature, among others, examines the federal and state government interventions during the Great Depression through debt moratoria of farm mortgages (Alston 1983, 1984; Rucker and Alston 1987) and impact on debtor value generated by the devaluation of debt contracts (Kroszner 1998, Vig 2013). 
Our work also relates to the literature on the housing and financial crisis (e.g., Mayer, Pence, and Sherlund 2009;2009; Mian and Sufi 2009; Barlevy and Fisher 2010; Keys et al. 2010 and Cassola, Hortaçsu, Kastl 2013). Our findings on the impact of government intervention in mortgage renegotiation are closely related to the work that examines loan renegotiation in mortgage markets (see Agarwal et al. 2011; Piskorski et al. 2010) and work that studies the effects of mortgage modification programs on household behavior (e.g., Mayer et al. 2014). It is also related to the studies evaluating the impact of foreclosures, falling house prices, and high levels of debt on economic outcomes (e.g., Melzer 2010; Mian et al. 2015; Campbell et al. 2011). ${ }^{35}$

Finally, our findings investigating the possibility of crowding-out of private activity by government intervention in the context of mortgage renegotiation broadly relate to the literature on government spending and Ricardian equivalence (e.g., Barro 1989; Johnson, Parker, and Souleles 2006; Agarwal et al. 2007; Mian and Sufi 2010; Parker 2011 and Nakamura and Steinsson 2014).

\section{Conclusion}

Our main conclusion is that intermediary-specific factors - which seem to be related to their pre-existing organizational capabilities-are an important determinant of foreclosures, impacting the propensity of millions of households to receive a loan modification. The presence of these factors - and the lack of understanding of their specific nature-poses a significant challenge to the ability of the government to quickly influence such intermediaries through provision of financial incentives, thus hampering policies that require voluntary participation of such firms. Our findings also suggest that the reallocation of resources that could promote more effective implementation of the program must have faced significant hurdles. Figuring out what these challenges that prevent reallocation of resources are, especially in times of crisis, is an interesting avenue for future research.

Our results have number of potential implications for the design of mortgage market and future policy interventions. First, in the case of HAMP, it may have been productive for the program to have allowed the easy transfer of distressed mortgages from inefficient servicers to those more capable of conducting many renegotiations. One way to address this issue in the future is to rely more on special servicers, as is commonly done in the commercial real estate market. There, upon the occurrence of certain specified adverse events, the non-performing loans are automatically transferred to organizations better equipped to handle such assets. Alternatively, some of the adjustments of loan terms during the crisis could be automatically incorporated in the mortgage contract terms, limiting the reliance on intermediaries (Piskorski and Tchistyi 2011; Eberly and Krishnamurthy 2014).

\footnotetext{
${ }^{35}$ See also recent research by Favilukis et al. (2015) on the origins of housing boom.
} 
Second, our analysis suggests that policies that rely on the voluntary participation of intermediaries need to recognize that certain organizations may be better equipped than others to implement a given initiative. Such policies are not limited only to loan modification programs but also apply to other initiatives undertaken by the administration in response to the recent crisis. $^{36}$

Third, our findings also provide guidance for designing large-scale renegotiation programs in the future. In particular, our evidence suggests that HAMP did not lead to widespread strategic defaults, likely because of the extensive screening related to its eligibility criteria and its design of incentives for servicers. However, these factors may also have stalled the pace of the program. Thus, there is a likely tradeoff between screening more intensively to reduce strategic behavior, which limits the unintended effects of the program, and the reach and pace of the program.

Finally, we note that because the costs (incentive payments) were triggered only by permanent HAMP modifications, one could use the ratio of estimated permanent modifications induced by the program to foreclosures prevented in assessing the program's success. ${ }^{37}$ Admittedly, this computation would be incomplete since it ignores other costs (or benefits) of program implementation, as well as any aggregate or redistributional effects in the economy. More generally, in the absence of a model of what optimal level of renegotiations and foreclosures should be, we cannot determine whether HAMP helped correct a "market failure." Devising such a model is a fruitful area of future research.

\section{References}

\footnotetext{
${ }^{36}$ For example, effective policies aimed at reducing the cost of debt through mortgage refinancing, such as HARP or quantitative easing initiatives, require significant refinancing activity by intermediaries.

${ }^{37}$ One could potentially perform a simple calculation to assess the net benefit of the program based on studies that quantify the deadweight losses of foreclosures. Abstracting from potential externalities of foreclosure prevention, the empirical studies suggests that the direct foreclosure cost could be in the order of $30 \%$ of the property value (e.g., Campbell et al 2010). Given the average property values of borrowers at risk of foreclosure during our sample period, this estimate would imply that preventing one foreclosure could save in the order of $\$ 50,000$. Such potential benefit could be compared with the direct financial cost of providing incentives for the additional HAMP modification (around \$4,000-6,000 in terms of servicer and investor payments and up to $\$ 5,000$ for borrower incentive payments per modification). As our results suggest that for one permanent modifications induced by the program there are about 0.55 fewer foreclosures, the above estimates suggests that up to about $\$ 11,000$ of direct incentive payment costs tied to one program modification are associated with about $\$ 27,000$ of savings due to fewer foreclosures. This simple comparison may suggest that the program benefits outweighed it costs. However, it is important to keep in mind that this is a very naive computation, since it ignores other costs (or benefits) of program implementation, including other administrative costs which are difficult to obtain data on, potential externalities of foreclosure prevention, as well as any aggregate or redistributional effects in the economy.
} 
Agarwal, Sumit, Chunlin Liu, and Nicholas S. Souleles. 2007. “The Reaction of Consumer Spending and Debt to Tax Rebates-Evidence from Consumer Credit Data.” Journal of Political Economy. 115 (December): 986-1019.

Agarwal, Sumit, Gene Amromin, Itzhak Ben-David, Souphala Chomsisengphet, and Douglas D. Evanoff. 2011. “The Role of Securitization in Mortgage Renegotiation.” Journal of Financial Economics. 102 (December): 559-578.

Alston, Lee. J. 1984. "Farm Foreclosure Moratorium Legislation: A Lesson from the Past." American Economic Review. 74 (June): 445-457.

Alston, Lee J. 1983. "Farm Foreclosures in the United States During the Interwar Period." Journal of Economic History. 43 (December): 885-903.

Barclays. 2008. Global Securitization Annual. 2 (January).

Barro, Robert J. 1989. "The Ricardian Approach to Budget Deficits. Journal of Economic Perspectives. 3 (Spring): 37-54

Barlevy, Gadi, and Jonas D. Fisher. 2010. “Mortgage Choice and House Speculation.” Federal Reserve Bank of Chicago. Working Paper no. 2010-12.

Bolton, Patrick, and Howard Rosenthal. 2002. "Political Intervention in Debt Contracts.” Journal of Political Economy. 110 (October): 1103-1134.

Campbell, John Y., Stefano Giglio, and Parag Pathak. 2011. "Forced Sales and House Prices.” American Economic Review. 101 (August): 2108-2131.

Cassola, Nuno, Ali Hortaçsu, and Jakub Kastl. 2013. “The 2007 Subprime Market Crisis Through the Lens of European Central Bank Auctions for Short-Term Funds.” Econometrica. 81 (July): 1309-1345.

Dinardo, John, and Jack Johnston. 1997. Econometric Methods, 4th edition. New York: McGraw-Hill.

Eberly, Janice, and Arvind Krishnamurthy. 2014. "Efficient Credit Polices in a Housing Crisis." Fall 2014 Brookings Panel on Economic Activity.

Favilukis, Jack, Sydney C. Ludvigson, and Stijn Van Nieuwerburgh. 2015. “The Macroeconomic Effects of Housing Wealth, Housing Finance, and Limited Risk-Sharing in General Equilibrium.” Journal of Political Economy (forthcoming).

United States Government Accountability Office. 2009. Report to Congressional Committees GAO-09-837 (July). 
Guiso, Luigi, Paola, Sapienza and Luigi Zingales. 2013. “The Determinants of Attitudes towards Strategic Default on Mortgages.” Journal of Finance. 68 (August): 1473-1515.

Haughwout, A., E. Okah, and J. Tracy. 2010. "Second Chances: Subprime Mortgage Modification and Re-Default.” Federal Reserve Bank of New York. Working Paper no. 417.

Haughwout, A., Donghoon Lee, Joseph Tracy, and Wilbert van der Klaauw. 2011. "Real Estate Investors, the Leverage Cycle, and the Housing Market Crisis.” Federal Reserve Bank of New York Staff Reports. no. 514.

Johnson, David S., Jonathan A. Parker, and Nicholas S. Souleles. 2006. "Household Expenditure and the Income Tax Rebates of 2001.” American Economic Review. 96 (December): 1589-1610.

Keys, Benjamin J., Tanmoy Mukherjee, Amit Seru, and Vikrant Vig. 2010. "Did Securitization Lead to Lax Screening: Evidence from Subprime Loans.” Quarterly Journal of Economics. 125 (February): 307-362.

Kroszner, Randall S. 1998. "Is It Better to Forgive than to Receive? Repudiation of the Gold Indexation Clause in Long-Term Debt During the Great Depression.” Working paper.

Kutcher, Theresa, and Johannes Stroebel. 2008. "Foreclosure and Bankruptcy - Policy Conclusions from the Current Crisis.” SIEPR Discussion Paper no. 08-37.

Mayer, Christopher, Karen Pence, and Shane Sherlund. 2009. “The Rise in Mortgage Defaults.” Journal of Economic Perspectives. 23 (Winter): 27-50.

Mayer, Christopher, Edward Morrison, and Tomasz Piskorski. 2009. “A New Proposal for Loan Modifications. Yale Journal on Regulation. 26: 417-429.

Mayer, Christopher, Edward Morrison, Tomasz Piskorski, and Arpit Gupta. 2014. "Mortgage Modification and Strategic Behavior: Evidence from a Legal Settlement with Countrywide.” American Economic Review. 104 (September): 2830-57.

Meyer, Bruce D. 1995. “Natural and Quasi-Experiments in Economics.” Journal of Business and Economic Statistics. 13 (April): 151-161.

Melzer, Brian. 2010. "Mortgage Debt Overhang: Reduced Investment by Homeowners with Negative Equity.” Working Paper.

Mian, Atif, and Amir Sufi. 2009. "The Consequences of Mortgage Credit Expansion: Evidence from the U.S. Mortgage Default Crisis.” Quarterly Journal of Economics. 124 (November): 1449-1496. 
Mian, Atif, and Amir Sufi. 2010. "The Effects of Fiscal Stimulus: Evidence from the 2009 'Cash for Clunkers' Program.” Quarterly Journal of Economics. 127 (September): 1107-1142.

Mian, Atif, Amir Sufi, and Francesco Trebbi, 2010, The Political Economy of the US Mortgage Default Crisis, American Economic Review, 100 (December): 1967-98.

Mian, Atif, Amir Sufi, and Francesco Trebbi. 2015. "Foreclosures, House Prices, and the Real Economy.” The Journal of the American Finance Association. 70 (November): 25872634.

Nakamura, Emi, and Jon Steinsson, 2014. "Fiscal Stimulus in a Monetary Union: Evidence from US Regions.” American Economic Review. 104 (March): 753-792.

Parker, Jonathan A., Nicholas S. Souleles, David S. Johnson, and Robert McClelland. 2011. "Consumer Spending and the Economic Stimulus Payments of 2008." Working Papers no. 16684, NBER, Cambridge, MA.

Parker, Jonathan. 2011. “On Measuring the Effects of Fiscal Policy in Recessions.” Journal of Economic Literature. 49 (September): 703-718.

Piskorski, Tomasz, Amit Seru, and Vikrant Vig. 2010. "Securitization and Distressed Loan Renegotiation: Evidence from the Subprime Mortgage Crisis.” Journal of Financial Economics. 97 (September): 369-397.

Piskorski, Tomasz, and Alexei Tchistyi. 2011. "Stochastic House Appreciation and Optimal Mortgage Lending.” Review of Financial Studies. 24 (February): 1407-1446.

Philippon, Thomas, and Virgiliu Midrigan. 2011. "Household Leverage and the Recession." Working Paper no. 16965, NBER, Cambridge, MA.

Posner, Eric, and Luigi Zingales. 2009. “A Loan Modification Approach to the Housing Crisis.” American Law and Economics Review. 11 (December): 575-607.

Rajan, Raghuram, and Rodney Ramcharan. 2015. "The Anatomy of a Credit Crisis: The Boom and Bust in Farm Land Prices in the United States in the 1920s.” American Economic Review. 105 (April): 1439-77.

Rucker, Randal R., and Lee J. Alston. 1987. "Farm Failures and Government Intervention: A Case Study of the 1930's.” American Economic Review. 77 (September): 724-730.

Scharfstein, David, and Adi Sunderam. 2011. "The Economics of Housing Finance Reform.” In The Future of Housing Finance, edited by Martin Neil Baily. Washington, D.C.: Brookings Institution Press. 
Syverson, Chad, 2011, What Determines Productivity?, Journal of Economic Literature, 49 (June): 326-365.

Vig, Vikrant. 2013. “Access to Collateral and Corporate Debt Structure: Evidence from a Natural Experiment.” Journal of Finance. 68 (May): 881-928. 


\section{Table 1: Summary Statistics for Control and Treatment Group in the Pre-Program Period}

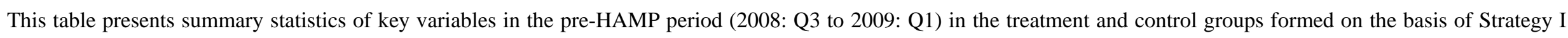

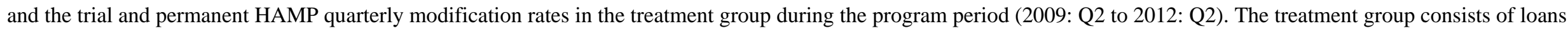
with owner-occupied status and with an outstanding balance below $\$ 729,750$, while the control group consists of loans with non-owner-occupied (investor) status.

\begin{tabular}{|c|c|c|c|c|}
\hline \multirow[t]{2}{*}{ Pre-program period: } & \multicolumn{2}{|c|}{ Control } & \multicolumn{2}{|c|}{ Treatment } \\
\hline & Mean & SD & Mean & SD \\
\hline FICO & 717 & 61.3 & 710 & 68.6 \\
\hline LTV \% & 70.3 & 18.9 & 70.6 & 20.3 \\
\hline Interest rate \% & 6.14 & 1.3 & 6.16 & 1.2 \\
\hline $60+$ delinquency rate \% [Quarterly] & 1.7 & 13.0 & 1.6 & 12.7 \\
\hline Private permanent modification rate \% [Quarterly] & 0.3 & 4.6 & 0.4 & 6.1 \\
\hline Foreclosure rate \% [Quarterly] & 0.4 & 6.4 & 0.3 & 5.2 \\
\hline Number of loans as of March 2009 & \multicolumn{2}{|c|}{$3,005,537$} & \multicolumn{2}{|c|}{$20,049,354$} \\
\hline Program period: & \multicolumn{4}{|c|}{ Trial HAMP Modifications } \\
\hline Trial HAMP modification rate (\%) [Quarterly] & \multicolumn{4}{|c|}{0.31} \\
\hline \multirow[t]{2}{*}{ Number of Trial HAMP modifications } & \multicolumn{4}{|c|}{752,179} \\
\hline & \multicolumn{4}{|c|}{ Permanent HAMP Modifications } \\
\hline Permanent HAMP modification rate (\%) [Quarterly] & \multicolumn{4}{|c|}{0.17} \\
\hline Number of Permanent HAMP modifications & \multicolumn{4}{|c|}{400,992} \\
\hline Conversion Rate: Trial to Permanent HAMP & \multicolumn{4}{|c|}{$53.3 \%$} \\
\hline
\end{tabular}




\section{Table 2: Impact of HAMP: Permanent Modification Rate}

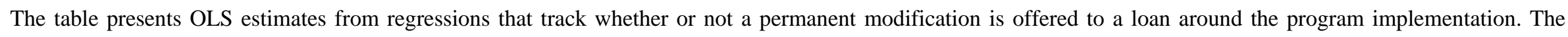

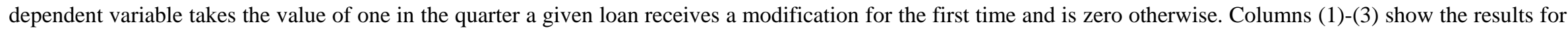

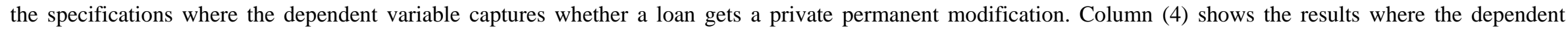

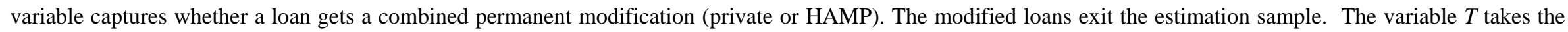

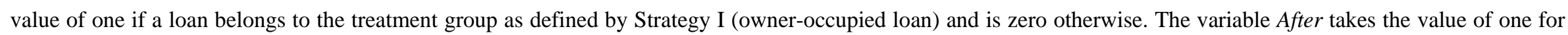

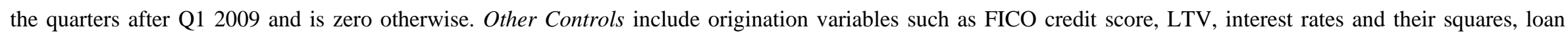

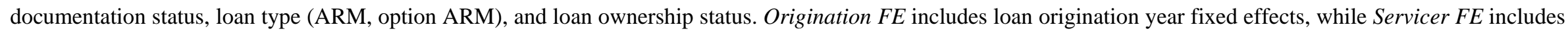

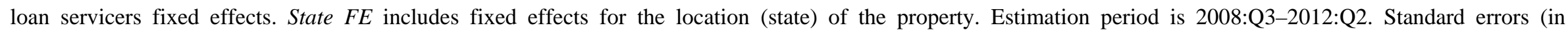
parentheses) are clustered at the state level. The estimates are expressed in percentage terms.

\begin{tabular}{|c|c|c|c|c|}
\hline & \multicolumn{3}{|c|}{$\begin{array}{c}\text { Dependent variable: } \\
\text { Whether a loan gets a private } \\
\text { permanent modification } \\
\text { in a quarter }\end{array}$} & \multirow{2}{*}{$\begin{array}{c}\text { Dependent variable: } \\
\text { Whether a loan gets a combined } \\
\text { permanent modification (private and } \\
\text { HAMP) in a quarter } \\
(4)\end{array}$} \\
\hline & (1) & (2) & (3) & \\
\hline \multirow[t]{2}{*}{$\mathrm{T}$} & 0.183 & 0.198 & 0.201 & 0.204 \\
\hline & $(0.023)$ & $(0.023)$ & $(0.030)$ & $(0.028)$ \\
\hline \multirow[t]{2}{*}{$\mathrm{T}^{*}$ After } & -0.028 & -0.027 & -0.025 & 0.142 \\
\hline & $(0.012)$ & $(0.012)$ & $(0.010)$ & $(0.017)$ \\
\hline \multirow[t]{2}{*}{ After } & 0.189 & 0.199 & 0.197 & 0.218 \\
\hline & $(0.020)$ & $(0.021)$ & $(0.021)$ & $(0.027)$ \\
\hline Observations & $288,244,979$ & $288,244,979$ & $288,244,979$ & $286,815,058$ \\
\hline Adj. $R$-square & 0.006 & 0.006 & 0.006 & 0.007 \\
\hline Other Controls & Yes & Yes & Yes & Yes \\
\hline Origination FE & Yes & Yes & Yes & Yes \\
\hline Servicer FE & No & Yes & Yes & Yes \\
\hline State FE & No & No & Yes & Yes \\
\hline
\end{tabular}




\section{Table 3: Impact of HAMP: Composition of Modifications and Default Conditional on a Modification}

The table presents OLS estimates from regressions that track the composition of modifications and the default rate conditional on a loan having received a modification around the program implementation. The sample consists of permanently modified loans. In Column (1) the dependent variable takes the value of one if a given loan modification includes rate reduction and is zero otherwise. In Column (2) the dependent variable takes the value of one if a given loan modification includes term extension and is zero otherwise. In Column (3) the dependent variable takes the value of one if a given loan modification includes principal write-down and is zero otherwise. In Column (4) the dependent variable takes the value of 1 if a given loan modification includes interest rate capitalization. In Column (5) the dependent variable takes the value of 1 if a loan status becomes 60 days past due or worse on payments in the first six months after modification and is 0 otherwise. The variable $T$ takes the value of 1 if a loan belongs to the treatment group as defined by Strategy I (owner-occupied loan) and is 0 otherwise. The variable After takes the value of 1 if the modification took place after Q1 2009 and is 0 otherwise. Other Controls include origination variables such as FICO credit score, LTV, interest rates and their squares, loan documentation status, loan type (ARM, option ARM), and loan ownership status. Origination FE includes loan origination fixed effects, while Servicer FE includes loan servicers fixed effects. State FE includes fixed effects for the location (state) of the property. The estimation period is 2008:Q3-2012:Q2. Standard errors (in parentheses) are clustered at the state level. The estimates are expressed in percentage terms. 


\begin{tabular}{|c|c|c|c|c|c|}
\hline & $\begin{array}{c}\text { Dependent variable: } \\
\text { Whether a modified loan in } \\
\text { gets a rate reduction }\end{array}$ & $\begin{array}{c}\text { Dependent variable: } \\
\text { Whether a modified loan } \\
\text { gets a term extension } \\
\end{array}$ & $\begin{array}{l}\text { Dependent variable: } \\
\text { Whether a modified loan in } \\
\text { gets a principal write-down }\end{array}$ & $\begin{array}{c}\text { Dependent variable: } \\
\text { Whether a modified loan } \\
\text { gets a capitalization } \\
\end{array}$ & $\begin{array}{c}\text { Dependent variable: } \\
\text { Whether a modified loan } \\
\text { defaults within six months }\end{array}$ \\
\hline & $(1)$ & $(2)$ & $(3)$ & (4) & (5) \\
\hline \multirow[t]{2}{*}{$\mathrm{T}$} & 9.04 & 1.21 & 1.08 & -7.24 & 0.56 \\
\hline & $(2.66)$ & $(1.51)$ & (0.379) & (1.48) & $(0.163)$ \\
\hline \multirow[t]{2}{*}{$\mathrm{T}^{*}$ After } & -10.14 & -8.33 & -2.26 & 9.06 & -0.31 \\
\hline & (3.87) & (3.44) & $(0.665)$ & $(2.58)$ & $(0.138)$ \\
\hline \multirow[t]{2}{*}{ After } & 28.63 & 18.53 & 3.53 & 8.28 & -8.88 \\
\hline & (3.67) & (4.09) & $(1.10)$ & $(2.58)$ & $(0.730)$ \\
\hline Observations & $1,902,481$ & $1,902,481$ & $1,902,481$ & $1,902,481$ & $1,902,481$ \\
\hline$R$-square & 0.17 & 0.25 & 0.67 & 0.24 & 0.01 \\
\hline Other Controls & Yes & Yes & Yes & Yes & Yes \\
\hline Origination FE & Yes & Yes & Yes & Yes & Yes \\
\hline Servicer FE & Yes & Yes & Yes & Yes & Yes \\
\hline State FE & Yes & Yes & Yes & Yes & Yes \\
\hline
\end{tabular}




\section{Table 4: Impact of HAMP: Foreclosure Rate}

The table presents OLS estimates from regressions that analyze whether or not a loan was foreclosed around the program implementation. The dependent variable takes the value of one in the quarter that a given loan is foreclosed (completed) and is zero otherwise. The foreclosed loans exit the estimation sample. The sample consists of all loans in columns (1)-(3) and delinquent loans in columns (4)-(6). The variable $T$ takes the value of one if a loan belongs to the treatment group as defined by Strategy I (owner-occupied loan), and is zero otherwise. The variable After takes the value of one for the quarters after Q1 2009 and is zero otherwise. Other Controls include origination variables such as FICO credit score, LTV, interest rates and their squares, loan documentation status, loan type (ARM, option ARM), and loan ownership status. Origination FE includes loan origination year fixed effects, while Servicer FE includes loan servicers fixed effects. State FE includes fixed effects for the location (state) of the property backing the loan. Estimation period is 2008:Q3-2012:Q2. Standard errors (in parentheses) are clustered at the state level. The estimates are expressed in percentage terms. 


\begin{tabular}{lcccccc}
\hline \hline & \multicolumn{5}{c}{ Dependent variable: Whether a loan was foreclosed in a quarter } \\
\cline { 2 - 7 } & $(1)$ & $(2)$ & $(3)$ & $(4)$ & $(5)$ & $(6)$ \\
\hline $\mathrm{T}$ & -0.163 & -0.150 & -0.129 & -1.547 & -1.374 & -1.335 \\
& $(0.031)$ & $(0.040)$ & $(0.035)$ & $(0.629)$ & $(1.16)$ & $(1.00)$ \\
$\mathrm{T}^{*}$ After & -0.093 & -0.095 & -0.094 & -1.683 & -1.615 & -1.689 \\
& $(0.030)$ & $(0.030)$ & $(0.030)$ & $(0.312)$ & $(0.296)$ & $(0.316)$ \\
After & 0.418 & 0.418 & 0.349 & 3.522 & 3.404 & 3.557 \\
& $(0.081)$ & $(0.080)$ & $(0.066)$ & $(0.575)$ & $(0.554)$ & $(0.571)$ \\
\hline Observations & $295,309,473$ & $295,309,473$ & $295,309,473$ & $34,162,468$ & $34,162,468$ & $34,162,468$ \\
Adj. - -square & 0.007 & 0.007 & 0.008 & 0.008 & 0.011 & 0.018 \\
\hline Other Controls & Yes & Yes & Yes & Yes & Yes & Yes \\
Origination FE & Yes & Yes & Yes & Yes & Yes & Yes \\
Servicer FE & No & Yes & Yes & No & Yes & Yes \\
State FE & No & No & Yes & No & No & Yes \\
\hline \hline
\end{tabular}




\section{Table 5: Alternative Empirical Strategy Exploiting Balance Eligibility Cutoff: Modifications, Redefault Rates, and Foreclosure Rates}

Panel A presents summary statistics of key variables in the pre-HAMP period (2008:Q3 to 2009:Q1) in the treatment and control groups formed using Strategy II and the trial and permanent HAMP quarterly modification rates in the treatment group during the program period 2009:Q2 to 2012:Q2. Owner-occupied loans with an amount outstanding below $\$ 729,750$ prior to the program announcement form the treatment group, while owner-occupied loans with a balance above this threshold form the control group. We restrict attention to loans that are within $\$ 100,000$ of the threshold. Panel B presents OLS estimates from regressions that track whether or not a permanent modification is offered to a loan, redefault rate conditional on receiving a modification, and whether or not the loan was foreclosed, around the program implementation in the treatment and control groups formed using Strategy II. Column (1) uses the dependent variable that takes the value of one in the quarter that a given loan receives the permanent private modification for the first time and is zero otherwise. Column (2) uses the dependent variable that takes the value of one in the quarter that a given loan receives the permanent modification (private or HAMP) for the first time and is zero otherwise. The modified loans exit the estimation sample. Column (3) presents the default estimates for the sample of permanently modified loans. The dependent variable takes the value of one if a loan status becomes 60 days past due or worse on payments in the first six months after modification and is zero otherwise. Columns (4) and (5) present the OLS estimates for the sample of all loans (Column 4) and the sample of delinquent loans (Column 5). The dependent variable takes the value of one in the quarter that a given loan is foreclosed and is zero otherwise. The foreclosed loans exit the estimation sample. The variable $T$ takes the value of one if a loan belongs to the treatment group and is zero otherwise. The variable After takes the value of one for the quarters after Q1 2009 and is zero otherwise. Other Controls include origination variables such as FICO credit score, LTV, interest rate and their squares, loan documentation status, loan type (ARM, option ARM), and loan ownership status. Origination FE includes loan origination year fixed effects, while Servicer FE includes loan servicers fixed effects. 
Estimation period is 2008:Q3-2012:Q2. Standard errors (in parentheses) are clustered at the state level. Estimates are expressed in percentage terms.

Panel A: Alternative Strategy: Summary Statistics for Control and Treatment Group

\begin{tabular}{|c|c|c|c|c|}
\hline \multirow[t]{2}{*}{ Pre-program period: } & \multicolumn{2}{|c|}{ Control } & \multicolumn{2}{|c|}{ Treatment } \\
\hline & Mean & SD & Mean & SD \\
\hline FICO & 729 & 50.6 & 728 & 51.7 \\
\hline LTV \% & 64.5 & 15.4 & 65.6 & 15.5 \\
\hline Interest rate \% & 5.52 & 1.7 & 5.48 & 1.7 \\
\hline $60+$ delinquency rate $\%$ [Quarterly] & 2.5 & 15.6 & 2.8 & 16.7 \\
\hline Private permanent modification rate \% [Quarterly] & 0.6 & 7.2 & 0.6 & 7.7 \\
\hline Foreclosure rate \% [Quarterly] & 0.2 & 4.7 & 0.2 & 4.8 \\
\hline Number of loans as of March 2009 & \multicolumn{2}{|c|}{65,259} & \multicolumn{2}{|c|}{132,732} \\
\hline Program period: & \multicolumn{4}{|c|}{ Trial HAMP Modifications } \\
\hline Trial HAMP modification rate (\%) [Quarterly] & \multicolumn{4}{|c|}{0.33} \\
\hline \multirow[t]{2}{*}{ Number of Trial HAMP modifications } & \multicolumn{4}{|c|}{6,568} \\
\hline & \multicolumn{4}{|c|}{ Permanent HAMP Modifications } \\
\hline Permanent HAMP modification rate (\%) [Quarterly] & \multicolumn{4}{|c|}{0.24} \\
\hline Number of Permanent HAMP modifications & \multicolumn{4}{|c|}{4,727} \\
\hline Conversion Rate: Trial to Permanent HAMP & \multicolumn{4}{|c|}{$71.9 \%$} \\
\hline
\end{tabular}


Panel B: Alternative Strategy: Modifications, Redefault Rates, and Foreclosure Rates

\begin{tabular}{|c|c|c|c|c|c|}
\hline & All loans & All loans & Modified loans & All loans & Delinquent loans \\
\hline & $\begin{array}{c}\text { Dependent variable: } \\
\text { Whether a loan gets a } \\
\text { private permanent } \\
\text { modification in a quarter }\end{array}$ & $\begin{array}{l}\text { Dependent variable: } \\
\text { Whether a loan gets a } \\
\text { combined permanent } \\
\text { modification in a quarter } \\
\text { (private and HAMP) }\end{array}$ & $\begin{array}{c}\text { Dependent variable: } \\
\text { Whether a modified loan } \\
\text { defaults within six months } \\
\text { after receiving a modification }\end{array}$ & $\begin{array}{l}\text { Dependent variable: } \\
\text { Whether a loan was } \\
\text { foreclosed in a quarter }\end{array}$ & $\begin{array}{l}\text { Dependent variable: } \\
\text { Whether a loan was } \\
\text { foreclosed in a quarter }\end{array}$ \\
\hline & (1) & $(2)$ & (3) & (4) & (5) \\
\hline $\mathrm{T}$ & $\begin{array}{c}0.004 \\
(0.023)\end{array}$ & $\begin{array}{c}-0.01 \\
(0.024)\end{array}$ & $\begin{array}{c}-0.08 \\
(0.040)\end{array}$ & $\begin{array}{c}0.03 \\
(0.027)\end{array}$ & $\begin{array}{c}0.19 \\
(0.132)\end{array}$ \\
\hline $\mathrm{T}^{*}$ After & $\begin{array}{c}-0.03 \\
(0.016)\end{array}$ & $\begin{array}{c}0.21 \\
(0.090)\end{array}$ & $\begin{array}{c}-0.07 \\
(0.057)\end{array}$ & $\begin{array}{c}-0.14 \\
(0.037)\end{array}$ & $\begin{array}{l}-2.19 \\
(0.39)\end{array}$ \\
\hline After & $\begin{array}{c}0.67 \\
(0.25)\end{array}$ & $\begin{array}{c}0.69 \\
(0.21)\end{array}$ & $\begin{array}{c}-4.41 \\
(0.579)\end{array}$ & $\begin{array}{c}0.70 \\
(0.224)\end{array}$ & $\begin{array}{c}2.95 \\
(1.59)\end{array}$ \\
\hline Observations & $2,568,737$ & $2,552,953$ & 27,502 & $2,695,608$ & 482,639 \\
\hline Adj. $R$-squared & 0.01 & 0.01 & 0.01 & 0.01 & 0.018 \\
\hline Other Controls & Yes & Yes & Yes & Yes & Yes \\
\hline Origination FE & Yes & Yes & Yes & Yes & Yes \\
\hline Servicer FE & Yes & Yes & Yes & Yes & Yes \\
\hline
\end{tabular}




\section{Table 6: Alternative Empirical Strategy Exploiting NPV Eligibility Test Cutoff: Impact on Foreclosure Rates}

In this table we examine the effect of permanent HAMP modification on foreclosure rate by analyzing the evolution of foreclosures in treatment group relative to the control group formed based on the HAMP Net Present Value (NPV) Test. To ensure that we have a tight set of comparable loans, we focus on applications that passed all other program eligibility criteria but differed on the final NPV test values, with these values all in the vicinity of zero (i.e., in the + or $-10 \%$ of the overall range of the NPV test). Among these loans, the treatment group is the set with NPV value greater than zero, while those with negative NPV value form the control group. The dependent variable takes the value of one if loan is foreclosed at a given horizon (one or three years) following NPV test and is zero otherwise. Treatment variable is a dummy that takes the value of one if a loan belongs to the treatment group and is zero otherwise. Columns (1)-(4) show the results for loans considered for a permanent modification under HAMP Tier 1 and Columns (5)-(6) show the results for loans considered for a permanent modification under HAMP Tier 2. Other Controls include origination variables such as FICO credit score, LTV, interest rate and their squares, loan documentation status, loan type. Standard errors (in parentheses); the estimates are expressed in percentage terms.

\begin{tabular}{|c|c|c|c|c|c|c|}
\hline & \multicolumn{4}{|c|}{ HAMP Tier 1} & \multicolumn{2}{|c|}{ HAMP Tier 2} \\
\hline & \multicolumn{2}{|c|}{$\begin{array}{c}\text { Dependent variable: } \\
\text { Whether foreclosure was completed } \\
\text { within } 1 \text { year after NPV Test }\end{array}$} & \multicolumn{2}{|c|}{$\begin{array}{c}\text { Dependent variable: } \\
\text { Whether foreclosure was completed } \\
\text { within } 3 \text { years after NPV Test }\end{array}$} & \multicolumn{2}{|c|}{$\begin{array}{c}\text { Dependent variable: } \\
\text { Whether foreclosure was completed } \\
\text { within } 1 \text { years after NPV Test }\end{array}$} \\
\hline & (1) & $(2)$ & (3) & (4) & (5) & (6) \\
\hline Treatment & $\begin{array}{l}-12.45 \\
(0.39) \\
\end{array}$ & $\begin{array}{c}-12.46 \\
(0.39)\end{array}$ & $\begin{array}{l}-28.28 \\
(0.51) \\
\end{array}$ & $\begin{array}{c}-28.20 \\
(0.51)\end{array}$ & $\begin{array}{l}-8.44 \\
(2.01) \\
\end{array}$ & $\begin{array}{l}-7.97 \\
(2.33)\end{array}$ \\
\hline Observations & 2,736 & 2,736 & 2,736 & 2,736 & 590 & 590 \\
\hline Adj. R-square & 0.036 & 0.041 & 0.103 & 0.109 & 0.029 & 0.106 \\
\hline Other Controls & No & Yes & No & Yes & No & Yes \\
\hline Origination FE & No & Yes & No & Yes & No & Yes \\
\hline State FE & No & Yes & No & Yes & No & Yes \\
\hline
\end{tabular}




\section{Table 7: Servicer Pre-HAMP Renegotiation Experience and HAMP Renegotiations}

Panel A shows the OLS estimates where the dependent variable takes the value 1 if a given loan received a trial HAMP (or permanent HAMP) modification during the program period and is 0 otherwise. Columns (1)-(4) show the results for treatment loans as defined by Strategy I. Column (5) and Column (6) show the results for treatment loans (as defined by Strategy I) in California and Florida, respectively. Column (7) shows the results for treatment loans as defined by Strategy II. The High Experience dummy takes the value of one if a loan is serviced by a servicer whose estimated renegotiation intensity in the pre-HAMP period is above median and is zero otherwise. Other Controls include FICO credit score, LTV, interest rates, their squares, loan doc status, loan type (ARM, option ARM), the loan ownership status, and the loan origination year fixed effects. State FE includes fixed effects for the location (state) of the property backing the loan. Estimation period 2008:Q3-2012:Q2. Standard errors (in parentheses) are clustered at the state level or at the zip code level (Column (5) and (6)). The estimates are expressed in percentage terms. In Panel B, we present correlation coefficients between the estimated renegotiation intensity of servicers prior to HAMP (pre-HAMP mod rate) and servicer organization variables. Full-time staff (FTE) is the number of employees employed in servicing the loans. Loans-per-FTE is the average number of loans serviced by an employee in a year. Average training hours refers to the hours dedicated by the servicing entity to training new (induction training) and old employees (continual training). \% calls dropped refer to the percentage of calls dropped by the call center receiving calls related to loan servicing. Phone hold time refers to the average hold time (in seconds) a customer has to wait on a servicing call. 
Panel A: Servicer Pre-HAMP Renegotiation Experience and HAMP Renegotiations

\begin{tabular}{|c|c|c|c|c|c|c|c|}
\hline & \multicolumn{2}{|c|}{$\begin{array}{c}\text { Sample: } \\
\text { Treatment loans } \\
\text { (Strategy I) }\end{array}$} & \multicolumn{2}{|c|}{$\begin{array}{c}\text { Sample: } \\
\text { Treatment loans } \\
\text { (Strategy I) }\end{array}$} & \multirow{2}{*}{$\begin{array}{c}\text { Sample: } \\
\text { Treatment loans } \\
\text { in California } \\
\text { (Strategy I) } \\
\text { Dependent variable: } \\
\text { Whether a loan gets a } \\
\text { permanent HAMP } \\
\text { modification }\end{array}$} & \multirow{2}{*}{$\begin{array}{c}\text { Sample: } \\
\text { Treatment loans } \\
\text { in Florida } \\
\text { (Strategy I) } \\
\text { Dependent variable: } \\
\text { Whether a loan gets a } \\
\text { permanent HAMP } \\
\text { modification }\end{array}$} & \multirow{2}{*}{$\begin{array}{c}\text { Sample: } \\
\text { Treatment loans } \\
\text { (Strategy II) } \\
\text { Dependent variable: } \\
\text { Whether a loan gets a } \\
\text { permanent HAMP } \\
\text { modification }\end{array}$} \\
\hline & $\begin{array}{r}\text { DependeI } \\
\text { Whether a lo } \\
\text { HAMP m }\end{array}$ & $\begin{array}{l}\text { variable: } \\
\text { gets a trial } \\
\text { dification }\end{array}$ & $\begin{array}{r}\text { Depender } \\
\text { Whether a } \\
\text { permane } \\
\text { modif } \\
\end{array}$ & $\begin{array}{l}\text { variable: } \\
\text { an gets a } \\
\text { HAMP } \\
\text { ation }\end{array}$ & & & \\
\hline \multirow{3}{*}{ High Experience } & (1) & $(2)$ & (3) & (4) & $(5)$ & $(6)$ & $(7)$ \\
\hline & 1.88 & 2.03 & 1.70 & 1.82 & 4.45 & 3.19 & 3.21 \\
\hline & $(0.56)$ & $(0.60)$ & $(0.41)$ & $(0.45)$ & $(1.01)$ & $(0.77)$ & $(0.56)$ \\
\hline Observations & $20,049,354$ & $20,049,354$ & $20,049,354$ & $20,049,354$ & $3,368,294$ & $1,213,040$ & 132,732 \\
\hline Adj. $R$-square & 0.033 & 0.038 & 0.022 & 0.026 & 0.035 & 0.022 & 0.048 \\
\hline Other Controls \& Origination FE & Yes & Yes & Yes & Yes & Yes & Yes & Yes \\
\hline State FE & No & Yes & No & Yes & - & - & Yes \\
\hline Zip Code FE & No & No & No & No & Yes & Yes & No \\
\hline
\end{tabular}

Panel B: Correlation between Servicer Pre-HAMP Renegotiation Experience and Servicer Organizational Variables

\begin{tabular}{|c|c|c|c|c|c|}
\hline & Full time staff (FTE) & Loans per FTE & Average training hours & \% Call dropped & Phone hold time (sec) \\
\hline & (1) & (2) & (3) & (4) & (5) \\
\hline Pre-HAMP mod rate & $52 \%$ & $-57 \%$ & $14 \%$ & $-43 \%$ & $-49 \%$ \\
\hline
\end{tabular}




\section{Table 8: Foreclosures, House Prices, Consumer Debt, and Durable (Auto) Consumption - Zip Code Level Analysis}

Panel A reports OLS estimates of regression where the dependent variable is the percentage of modified loans under the program in a zip code. The variable High Servicer Share is the fraction of loans serviced by high experience servicers in a zip code prior to the program implementation (based on our classification). Column (1) presents results for an overall sample of zip codes, while Column (2) and (3) present the results for the matched sample of zip codes. Panel B reports OLS estimates of regressions evaluating the relationship between exposure to HAMP in a zip code and the change in foreclosure rate (1)-(2), the house price growth rate rate (3)-(4), consumer debt delinquency rate (5)-(6), and auto sales (durable spending) growth rate (7)-(8). The change is between the program period (2009:Q2 to 2012:Q4) and the pre-program period (2008:Q3 to 2009:Q1). The sample consists of matched zip codes as explained in Section VIII.A. The estimates are scaled by one standard deviation of the High Servicer Share variable and expressed in percentage terms; standard errors in parentheses.

Panel A: Zip Code Ex Post HAMP Modifications and Ex Ante Exposure to HAMP (Share of Loans Serviced by High Experience Servicers)

\begin{tabular}{|c|c|c|c|}
\hline & \multicolumn{3}{|c|}{ Percentage of loans modified under HAMP } \\
\hline & \multirow{2}{*}{$\begin{array}{c}\text { All loans } \\
(1)\end{array}$} & \multicolumn{2}{|c|}{ Matched Sample } \\
\hline & & $(2)$ & (3) \\
\hline \multirow[t]{2}{*}{ High Servicer Share } & 0.43 & 0.81 & 0.79 \\
\hline & $(0.02)$ & $(0.09)$ & $(0.09)$ \\
\hline Propensity Score Controls & No & No & Yes \\
\hline Mean HAMP Percentage & 2.41 & 3.85 & 3.85 \\
\hline Number of Observations & 9,999 & 704 & 704 \\
\hline Adj. $R$-squared & 0.04 & 0.09 & 0.16 \\
\hline
\end{tabular}


Panel B: Zip Code Outcomes and Ex Ante Exposure: Foreclosures, House Prices, Consumer Debt, Delinquency, and Durable (Auto) Consumption

\begin{tabular}{|c|c|c|c|c|c|c|c|c|}
\hline & \multicolumn{2}{|c|}{$\begin{array}{c}\text { Foreclosure } \\
\text { rate } \\
\end{array}$} & \multicolumn{2}{|c|}{ HPI growth } & \multicolumn{2}{|c|}{$\begin{array}{c}\text { Consumer debt } \\
\text { Delinquency }\end{array}$} & \multicolumn{2}{|c|}{$\begin{array}{c}\text { Auto sales } \\
\text { growth }\end{array}$} \\
\hline & (1) & (2) & (3) & (4) & (5) & (6) & (7) & (8) \\
\hline \multirow[t]{2}{*}{ High Servicer Share } & -0.08 & -0.08 & 0.24 & 0.24 & -0.26 & -0.24 & 0.52 & 0.49 \\
\hline & $(0.02)$ & $(0.02)$ & $(0.12)$ & $(0.11)$ & $(0.05)$ & $(0.04)$ & $(0.16)$ & $(0.16)$ \\
\hline Propensity Score Controls & No & Yes & No & Yes & No & Yes & No & Yes \\
\hline Adj. $R$-squared & 0.02 & 0.24 & 0.01 & 0.22 & 0.04 & 0.27 & 0.01 & 0.06 \\
\hline
\end{tabular}




\section{Figure 1: Comparability of Treatment and Control Groups -- Kernel Density of Observables}

The figure shows the kernel density plots for (a) loan origination FICO credit score, (b) interest rate, and (c) Loan to Value (LTV) in the treatment and control groups defined using Strategy I (owner-occupancy status). The treatment group is represented by the solid line, and the control group is represented by the dashed line.

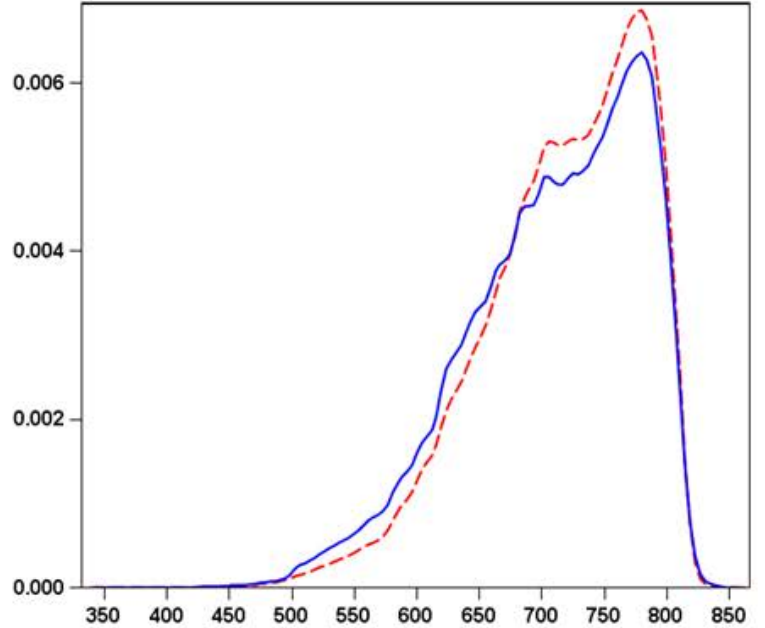

1(a): FICO credit score

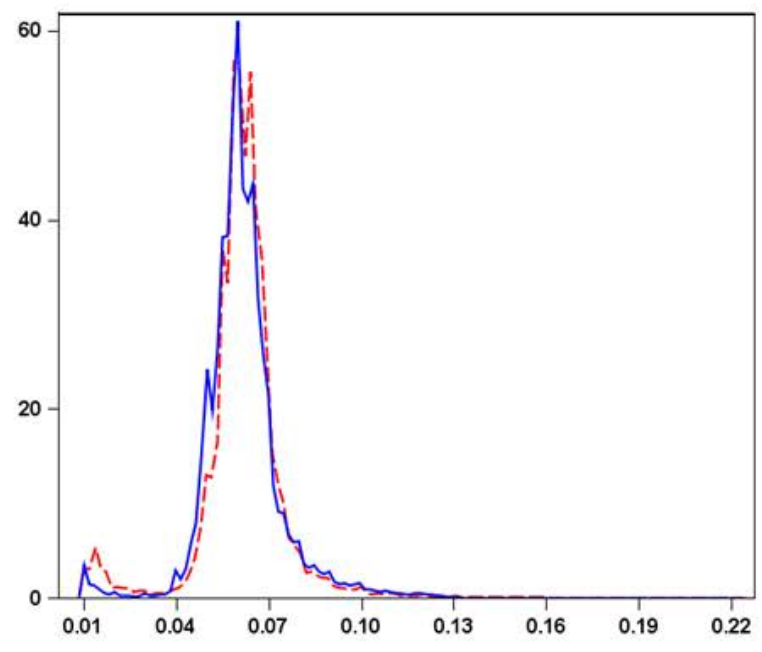

1(b): Interest rate

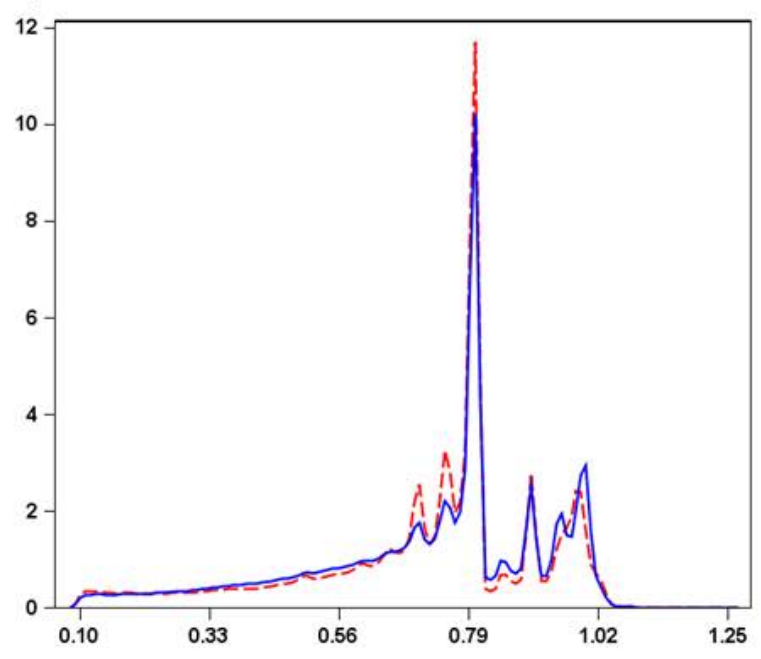

1(c): Loan to Value (LTV) 


\section{Figure 2: Evolution of Private, HAMP, and Combined (Private and HAMP) Modification Rates}

Panel (a) of the figure shows the percentage of loans receiving a trial (dashed line) and permanent (solid line) HAMP modification for the first time in a given month in the treatment group defined using Strategy I. Panel (b) shows the percentage of loans receiving a permanent private modification for the first time in a given month in the treatment and control groups defined using Strategy I. Panel (c) shows the percentage of loans receiving a combined permanent modification (private and HAMP) in these groups. In Panels (b) and (c) the treatment group is represented by the solid line, and the control group is represented by the dashed line.

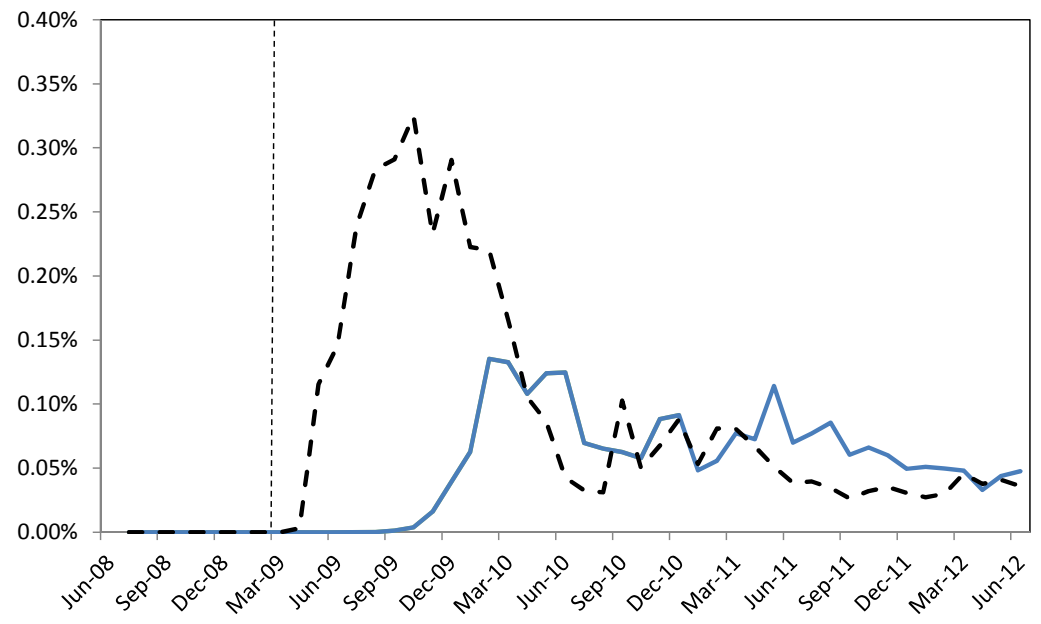

2(a): Trial and permanent HAMP modification

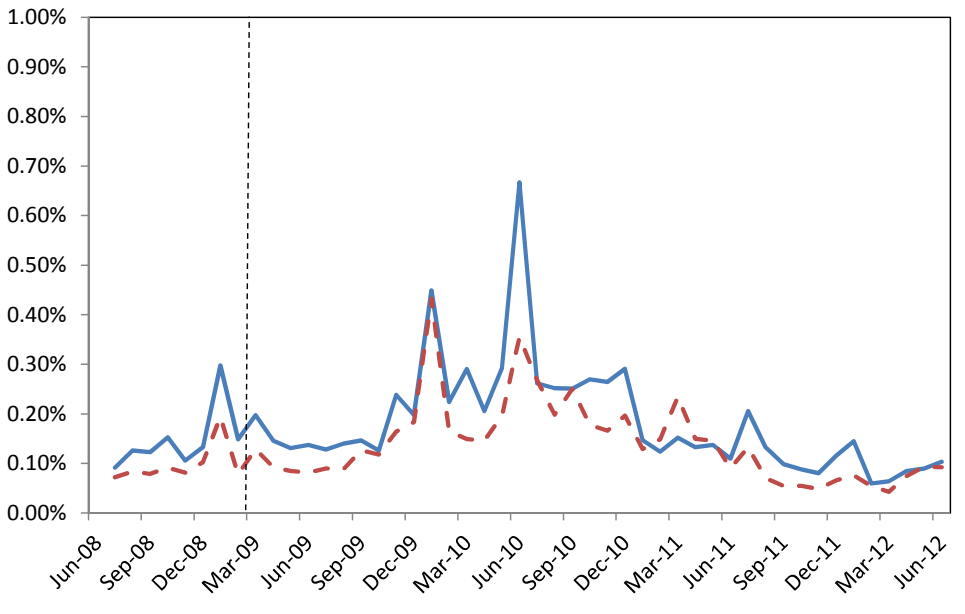

2(b): Private permanent modification

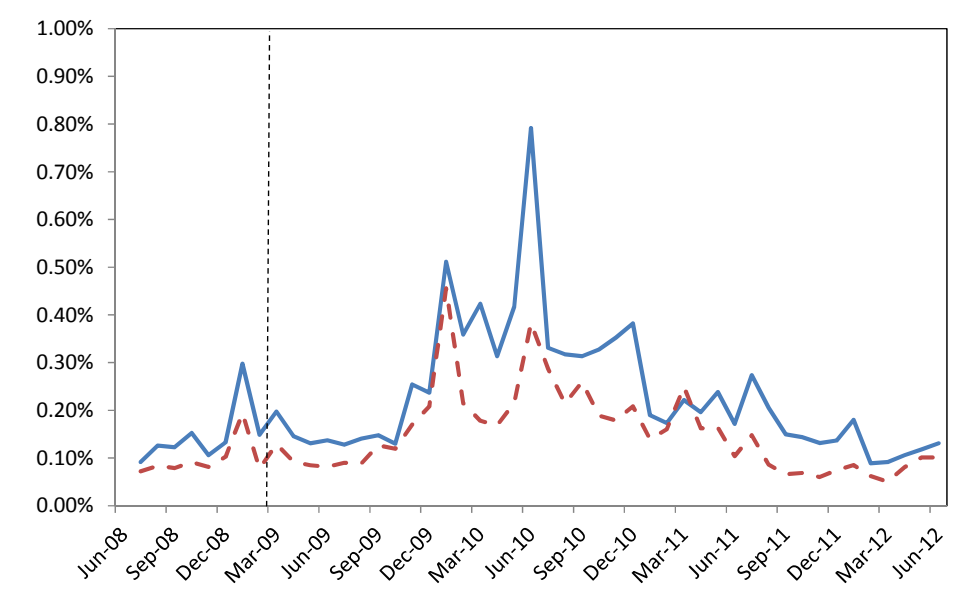

2(c): Combined private and HAMP permanent modification 


\section{Figure 3: Alternative Strategy: Evolution of Private, HAMP, and Combined (Private and HAMP) Modification Rates}

Panel (a) of the figure shows the percentage of loans receiving a trial (dashed line) and permanent (solid line) HAMP modification for the first time in a given month in the treatment group defined using Strategy II. Panel (b) shows the percentage of loans receiving a permanent private modification for the first time in a given month in the treatment and control groups defined using Strategy II. Panel (c) shows the percentage of loans receiving a combined permanent modification (private and HAMP) in these groups. In Panels (b) and (c) the treatment group is represented by the solid line, and the control group is represented by the dashed line.

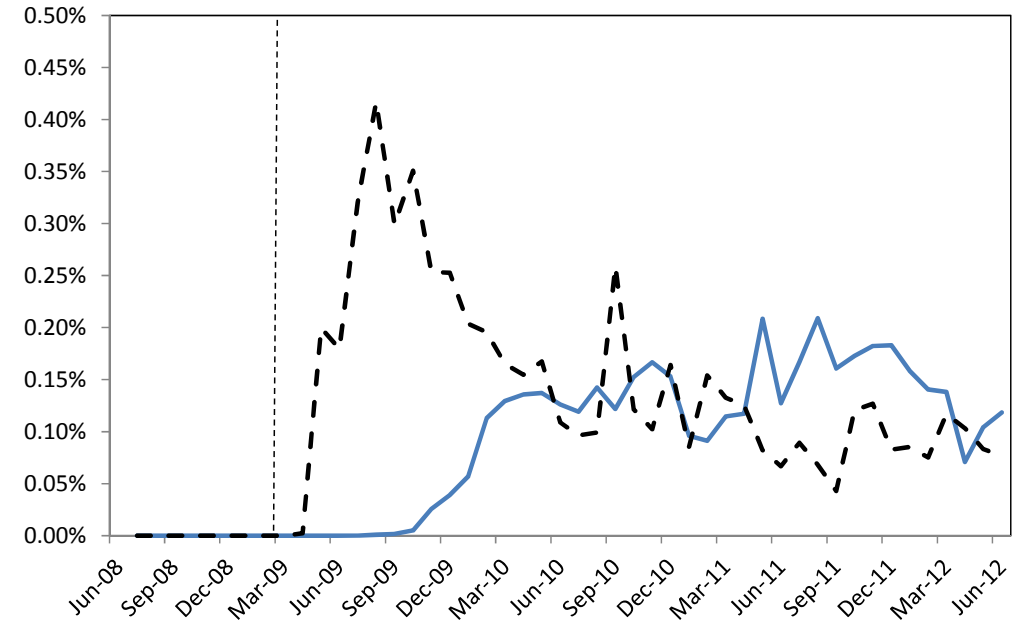

3(a): Trial and permanent HAMP modification

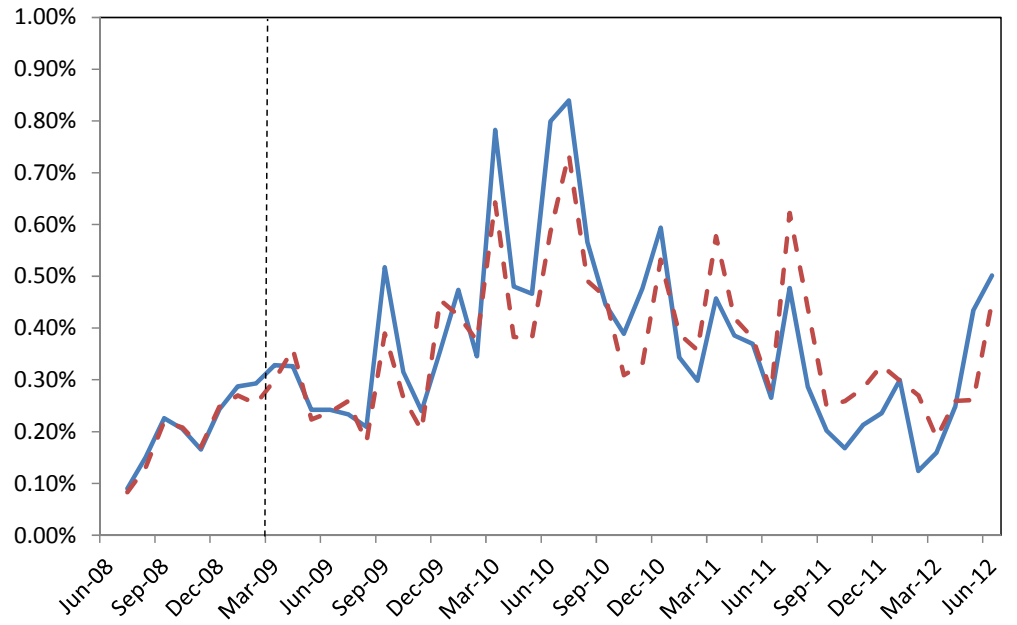

3(b): Private permanent modification

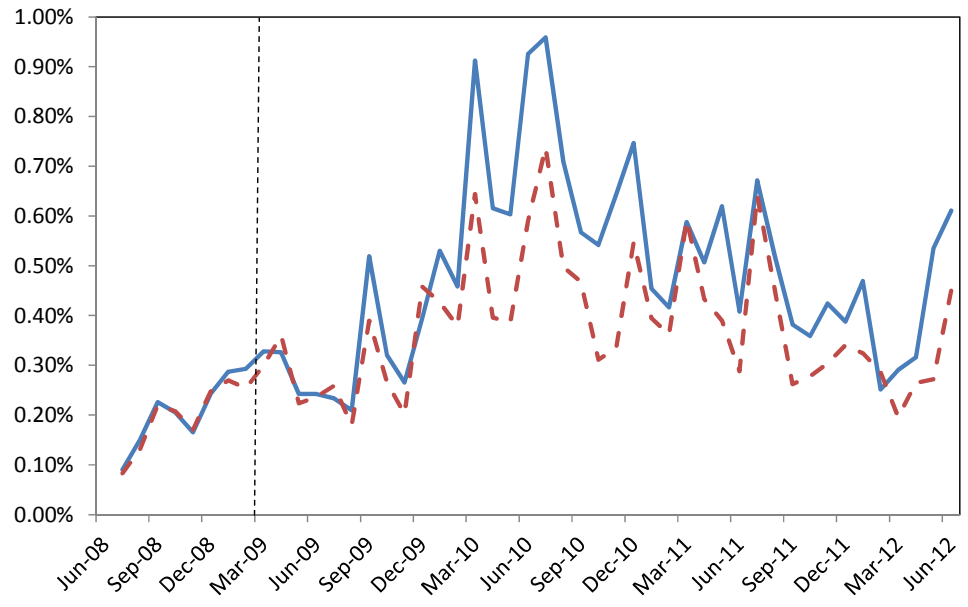

3(c): Combined private and HAMP permanent modification 
Figure 4: Quarterly HAMP Modification Rates and Pre-HAMP Private Modification Rates across Servicers

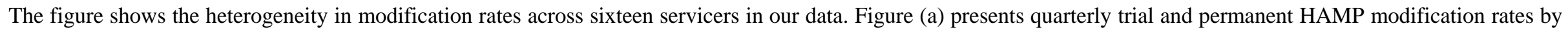

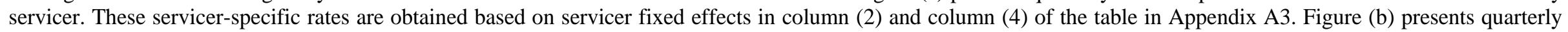

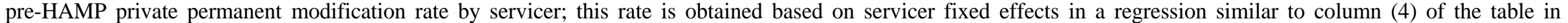
Appendix A3 but estimated on pre-HAMP data.

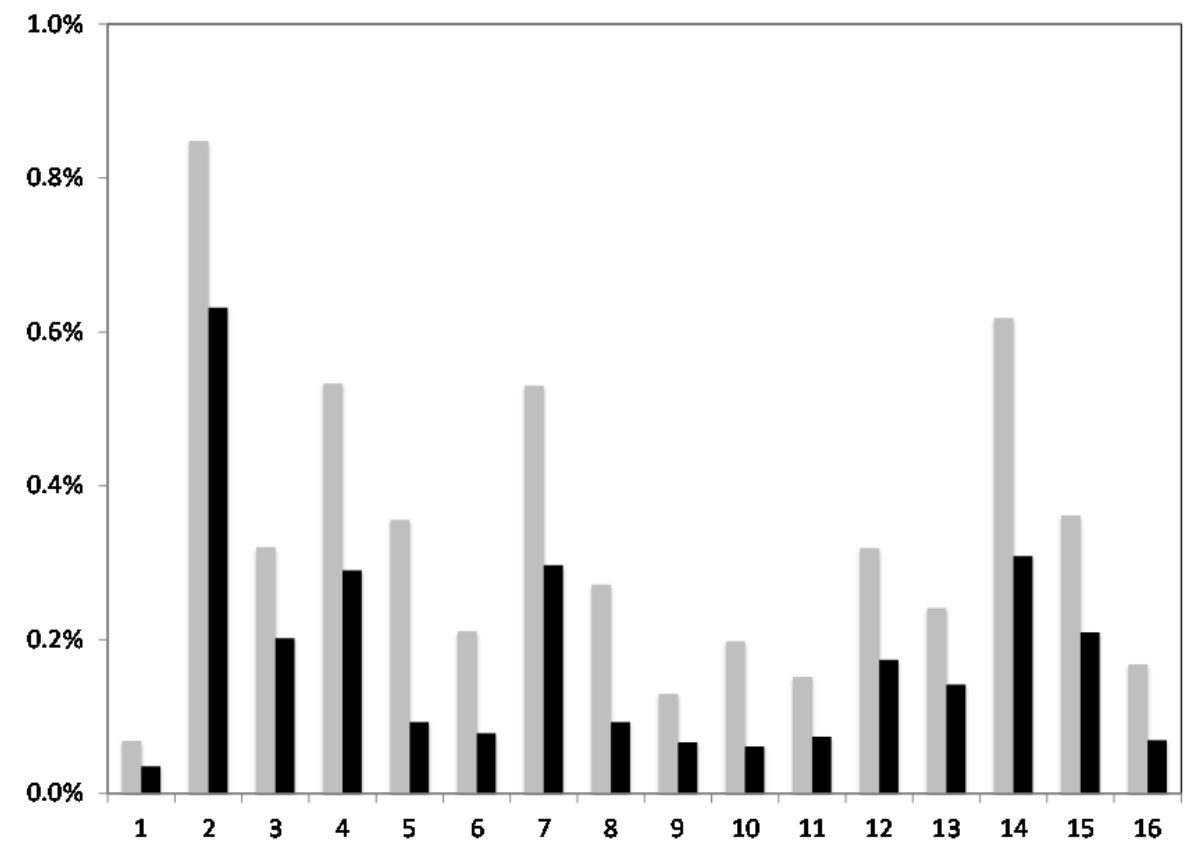

4(a): Trial (grey) and permanent (black) HAMP modification rates

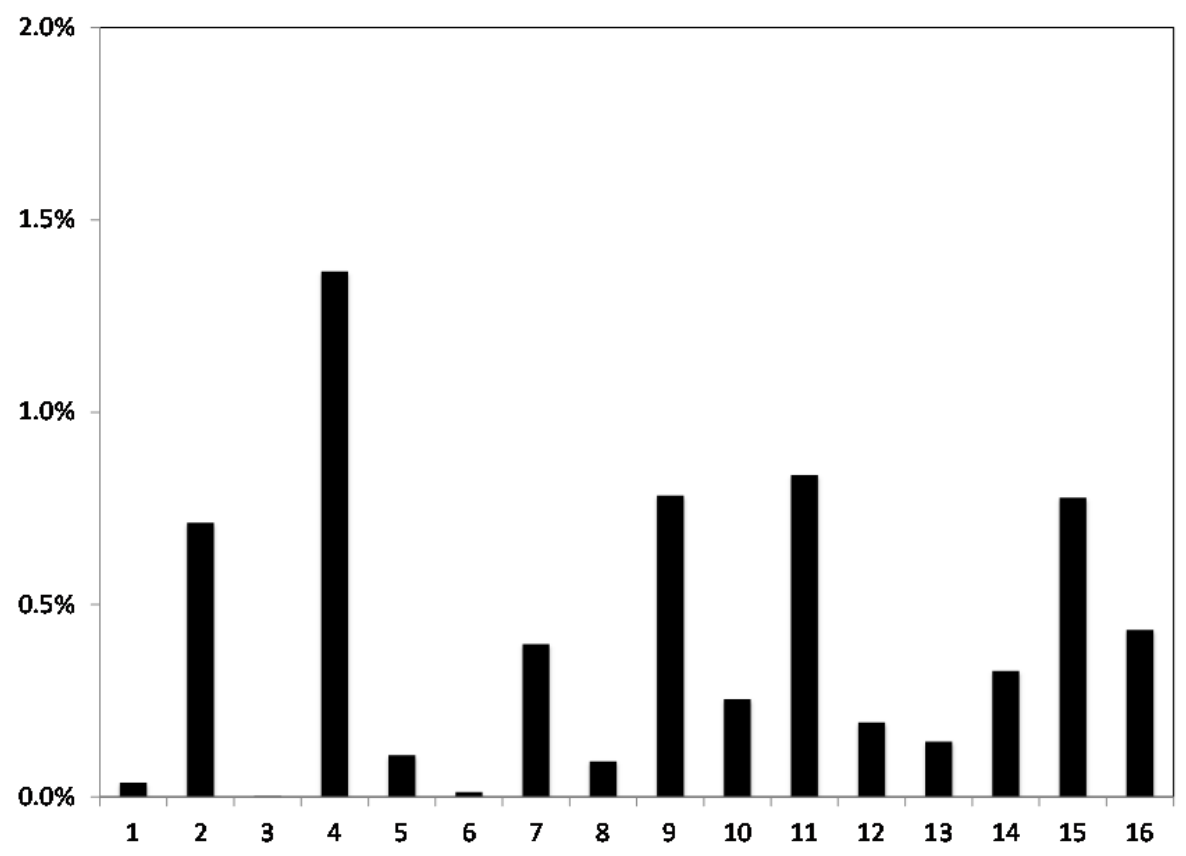

4(b): Pre-HAMP permanent modification rates 
Figure 5: Quarterly HPI Growth, Auto Sales Growth, and Consumer Credit Delinquency Rates in High and Low Exposure Zip Codes

The figure shows the average house price growth rates (Panels (a) and (b)), the delinquency rate on all consumer accounts (Panel (c)), and auto sales growth (Panel (d)) in the high and low exposure groups in the matched zip code sample. Zip-code-level house price growth is computed using CoreLogic (Panel (a)) and CoreLogic excluding distressed sales (Panel (b)) price indices, the rate of consumer delinquencies on all accounts is from Equifax (Panel (c)), and auto sales growth data come from Mian and Sufi (2010) (Panel (d)). The high exposure group is represented by the solid line, and the low exposure group is represented by the dashed line.

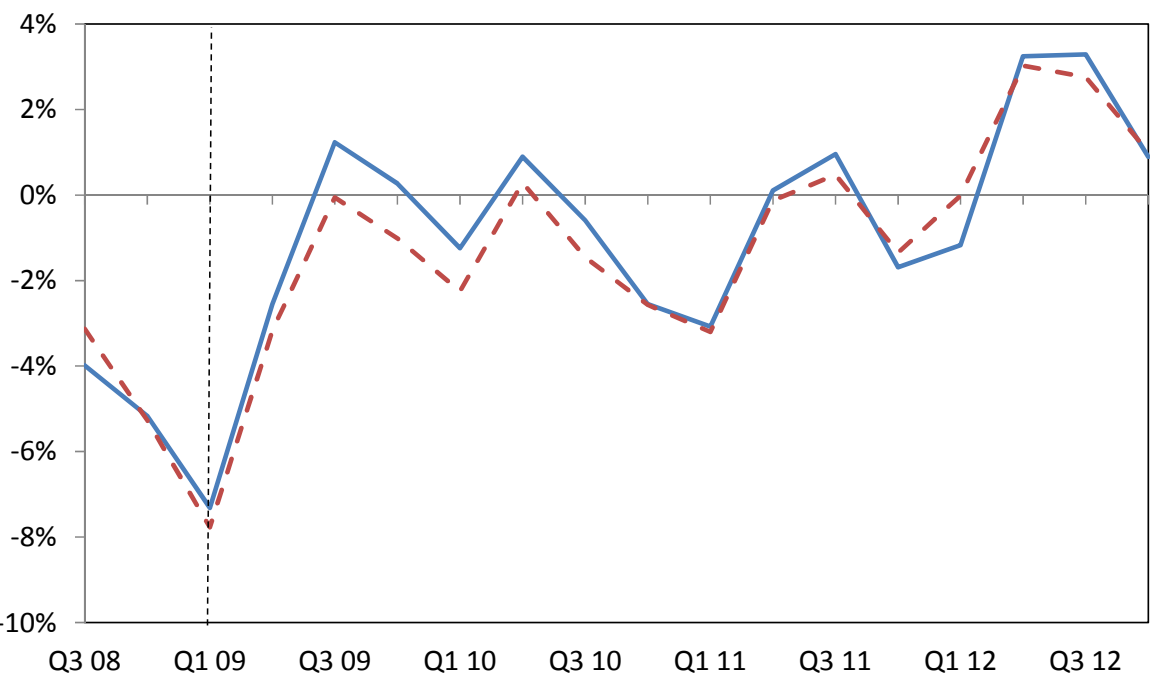

5(a): House price growth

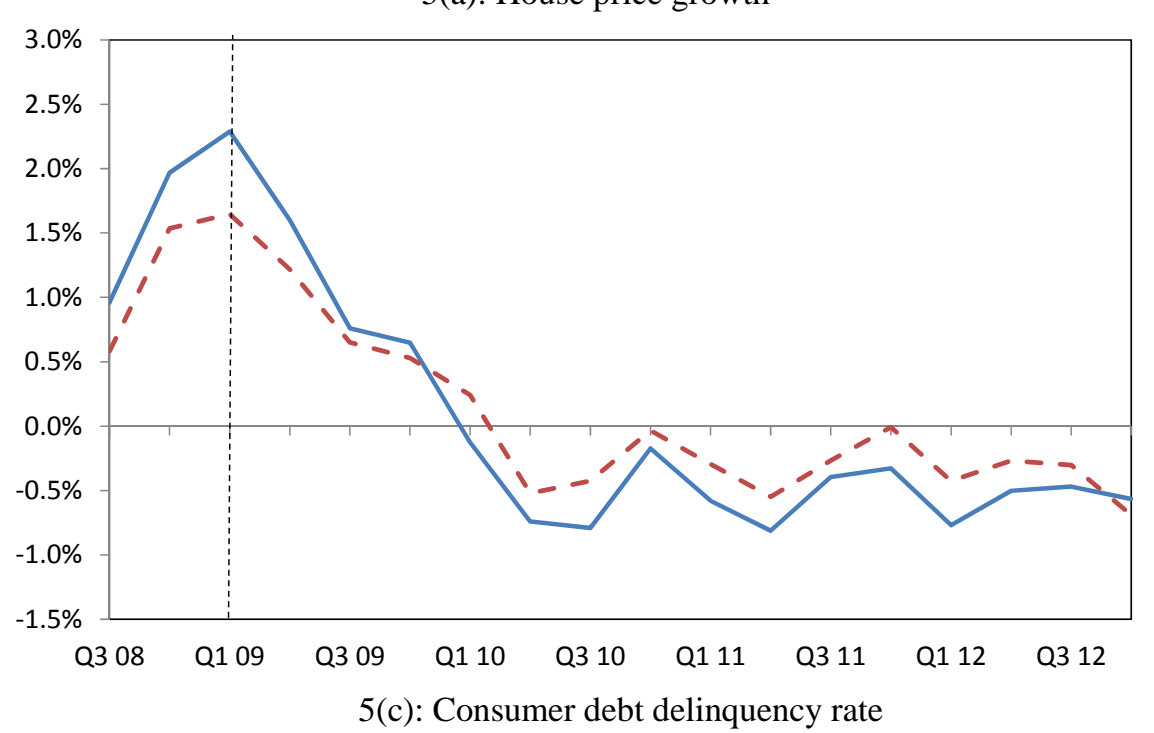

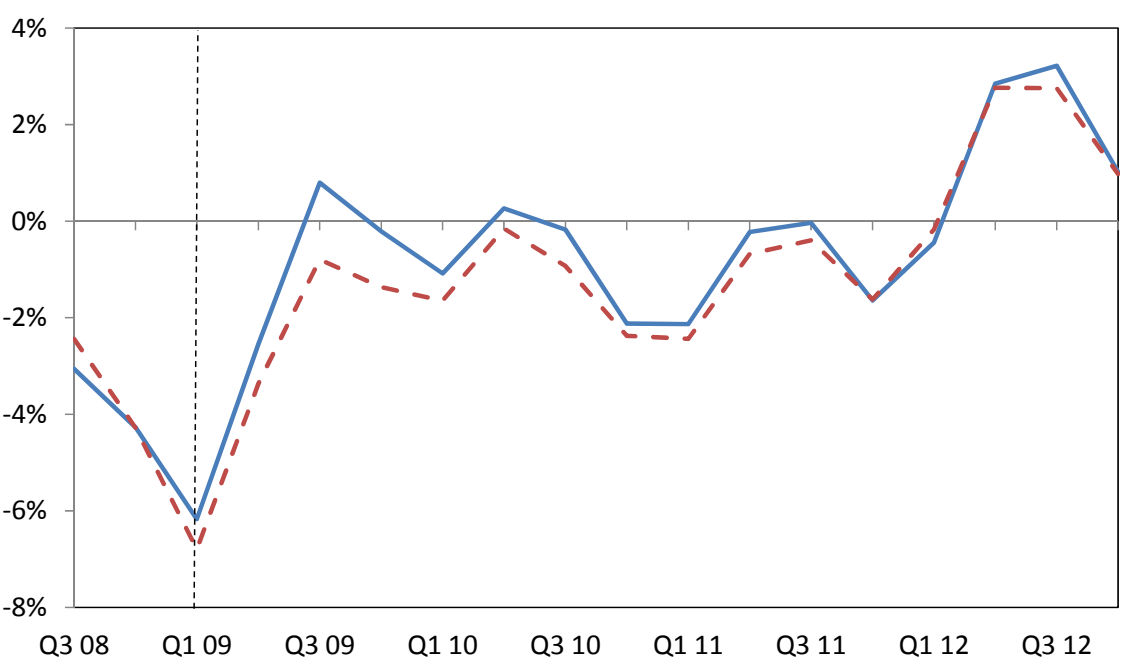

5(b): House price growth (excluding distressed sales)

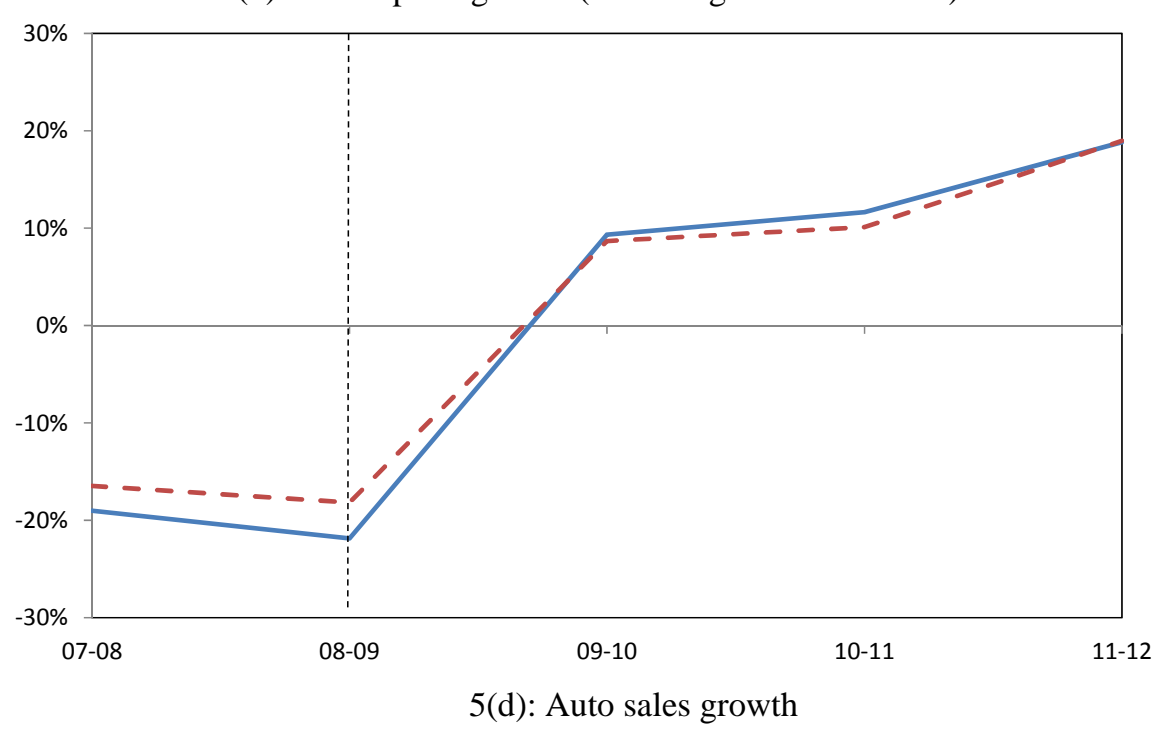


